IZA DP No. 9998

Choosing a Partner for Social Exchange:

Charitable Giving as a Signal of Trustworthiness

Sebastian Fehrler

Wojtek Przepiorka

June 2016 


\title{
Choosing a Partner for Social Exchange: Charitable Giving as a Signal of Trustworthiness
}

\author{
Sebastian Fehrler \\ University of Konstanz \\ and IZA
}

\author{
Wojtek Przepiorka \\ Utrecht University \\ and Nuffield College
}

\section{Discussion Paper No. 9998 \\ June 2016}

\author{
IZA \\ P.O. Box 7240 \\ 53072 Bonn \\ Germany \\ Phone: +49-228-3894-0 \\ Fax: +49-228-3894-180 \\ E-mail: iza@iza.org
}

\begin{abstract}
Any opinions expressed here are those of the author(s) and not those of IZA. Research published in this series may include views on policy, but the institute itself takes no institutional policy positions. The IZA research network is committed to the IZA Guiding Principles of Research Integrity.

The Institute for the Study of Labor (IZA) in Bonn is a local and virtual international research center and a place of communication between science, politics and business. IZA is an independent nonprofit organization supported by Deutsche Post Foundation. The center is associated with the University of Bonn and offers a stimulating research environment through its international network, workshops and conferences, data service, project support, research visits and doctoral program. IZA engages in (i) original and internationally competitive research in all fields of labor economics, (ii) development of policy concepts, and (iii) dissemination of research results and concepts to the interested public.
\end{abstract}

IZA Discussion Papers often represent preliminary work and are circulated to encourage discussion. Citation of such a paper should account for its provisional character. A revised version may be available directly from the author. 
IZA Discussion Paper No. 9998

June 2016

\section{ABSTRACT \\ Choosing a Partner for Social Exchange: Charitable Giving as a Signal of Trustworthiness*}

People benefit from being perceived as trustworthy. Examples include sellers trying to attract buyers, or candidates in elections trying to attract voters. In a laboratory experiment using exchange games, in which the trustor can choose the trustee, we study whether trustees can signal their trustworthiness by giving to charity. Our results show that donors are indeed perceived as more trustworthy and they are selected significantly more often as interaction partners. As a consequence of this sorting pattern, relative payoffs to donors and non-donors differ substantially with and without partner choice. However, we do not find donors to be significantly more trustworthy than non-donors. Our findings suggest that publicly observable generosity, such as investments in corporate social responsibility or donations to charity during a political campaign, can induce perceptions of trustworthiness and trust.

JEL Classification: $\quad$ C92, H41

Keywords: costly signaling, social preferences, trust, trustworthiness, partner choice, corporate social responsibility, electoral competition

Corresponding author:

Sebastian Fehrler

University of Konstanz

Box 131

78457 Konstanz

Germany

E-mail: sebastian.fehrler@uni-konstanz.de

\footnotetext{
* Forthcoming in the Journal of Economic Behavior \& Organization. Authors' names are listed in alphabetical order. Both authors contributed equally to this work.
} 


\section{Introduction}

Finding trustworthy partners is important in many domains of social and economic life. Examples abound: customers looking for trustworthy sellers, employers looking for trustworthy employees, and voters looking for trustworthy candidates. For trustees, who benefit from being selected as interaction partners, it is crucial to convince trustors of their trustworthiness. ${ }^{1}$ How can they achieve this? One way could be for trustworthy trustees to engage in observable behavior that credibly signals their trustworthiness and sets them apart from less trustworthy competitors (Bacharach and Gambetta 2001; Raub 2004; Bolle and Kaehler 2007; Przepiorka and Diekmann 2013). In the context of firms, it has been argued that corporate social responsibility (CSR) might serve as a signal of trustworthiness (Vlachos et al. 2008; Elfenbein et al. 2012), and other studies suggest that charitable giving by candidates might serve the same purpose in political competitions (Milinski et al. 2002; Hamman et al. 2011). Consistent with these conjectures, Fehrler and Przepiorka (2013) show, in an experiment with a modified trust game, that subjects transfer more to donors because they expect donors to be more trustworthy than non-donors.

While trust in and trustworthiness of trustees with different characteristics has been studied extensively (for an overview see Fehr 2009), partner choice has received much less scholarly attention. In most trust experiments subjects cannot choose their interaction partners; they are randomly paired with each other. In these experiments, trust levels have been shown to vary considerably with trustees' observable characteristics (e.g., McEvily et al. 2012). This is not surprising as trust largely depends on trustors' expectations of trustees' trustworthiness. It seems likely therefore that trustors' beliefs would also affect their choice of trustees. According to this sorting hypothesis (Slonim and Garbarino 2008) it can be expected that trustees who receive higher transfers when randomly paired with a trustor will also be chosen more often as interaction partners when trustors can choose trustees.

We study trustors' choices of, and transfers to, trustees in an exchange game (a modified trust game) where trustees differ in whether or not they have donated part of their endowment to charity. We study two scenarios, one in which trustors can choose trustees (partner choice) and

\footnotetext{
${ }^{1}$ As is standard in the literature on trust, we call those in whom trust may or may not be placed 'trustees', and we call those who may or may not have trust in others 'trustors'.
} 
one in which trustors and trustees are randomly paired (random matching). To understand the role of beliefs, we elicit trustors' expectations regarding back transfers in the exchange game from the different types of trustees. To isolate trust from other motives which might also affect partner choices and transfers in our exchange game, we employ further experimental conditions. We measure trustors' choices and transfers in a dictator game, and we employ conditions in which trustees do not have the option to donate but differ in their endowment. Using a withinsubject design, we can study the motives behind subjects' behavior at the individual level. Our key findings can be summarized as follows:

1) Donors to charity are chosen more often as trustees and receive higher transfers in the exchange game than non-donors. They are perceived as more trustworthy.

2) Donors to charity are neither more nor less trustworthy than non-donors, and charitable donations do not pay off in monetary terms.

3) Differences in the transfers that donors and non-donors receive are much more pronounced in the case of partner choice than in the case of random matching.

4) The sorting hypothesis is supported, on average. The trustees subjects choose in the partner choice part of the experiment are of the same type as those to which they transfer more in the random matching part. However, a substantial number of subjects do not behave in line with the sorting hypothesis.

Our first finding suggests that charitable giving may work as a signal of trustworthiness. Our third finding demonstrates that outcome differences between potential partners in social exchange will be underestimated if partner choice is not accounted for. The more pronounced differences in the partner choice part of the experiment occur despite the fact that some subjects' behavior is not in line with the sorting hypothesis (finding 4).

The next section relates our study to previous literature. The description of the experimental design in Section 3 is followed by the presentation of our results in Section 4. The last section summarizes our main findings and discusses the interpretation of CSR and charitable donations during electoral campaigns as signals of trustworthiness. 


\section{Related literature}

\subsection{Signaling trustworthiness}

A trustee can be trustworthy because she is committed to acting in the trustor's interest out of self-interest, e.g. in a repeated interaction (e.g., Camerer and Weigelt 1988; Anderhub et al. 2002; Bolton et al. 2004a; Bracht and Feltovich 2009), or because of other-regarding preferences, reciprocity or trust responsiveness (e.g., McCabe et al. 2003; Cox 2004; Bolton et al. 2004b; Bacharach et al. 2007; Battigalli and Dufwenberg 2009; Toussaert 2014). Theoretical models (e.g., Fehr and Schmidt 1999) and empirical evidence (e.g., Ashraf et al. 2006) both suggest that trustees who are trustworthy because of other-regarding preferences will also be more generous, e.g., in a dictator game, even if such generosity has no instrumental value (Gambetta and Przepiorka 2014; Przepiorka and Liebe 2016). In an earlier study, Fehrler and Przepiorka (2013) show that donors to charity indeed tend to be more trustworthy than nondonors (see also Albert et al. 2007). Game-theoretic models illustrating the idea that charitable giving can work as a signal of trustworthiness have been proposed by Elfenbein et al. (2012) and Ong and Yang (2014) (see also Gintis et al. 2001; Gambetta and Przepiorka 2014).

Elfenbein et al. (2012) also present convincing empirical evidence of how charitable giving can work as a signal of trustworthiness. They analyze a large data set of eBay offers - many of which were posted under eBay's Giving Works program, where sellers dedicate a fraction of the selling price to a charity. Their data includes offers of identical products from the same sellers under the program and outside of it, allowing them to conduct a quasi-experimental analysis. Consistent with a costly signaling account, they observe a higher percentage increase in sales and prices under the Giving Works program for sellers without a reliable reputation, i.e., with a short history of customer feedback. Their results suggest that the charitable element serves as a substitute for an established reputational record. Moreover, they find that sellers who use the Giving Works program receive fewer customer complaints, suggesting that they are indeed more trustworthy. Finally, they find that the higher sales and prices these sellers attain do not fully compensate them for the costs of the donation.

On eBay and other trading platforms buyers can choose the sellers they trust. In most lab experiments with trust games, trustors are randomly matched with trustees and cannot choose their interaction partner. There are a few notable exceptions. 


\subsection{Partner choice}

Slonim and Garbarino (2008) conduct an online experiment in which they test the effect of partner choice on subjects' investment game and dictator game transfers to interaction partners who differ by age and gender. They predict that in both games, if subjects have the possibility to choose their interaction partner, they will, on average, transfer higher amounts than had they been randomly paired with the same interaction partner. Slonim and Garbarino hypothesize this difference to be due to a sorting effect according to which subjects will choose certain partners because they want to transfer more to them, and the partners they choose are also those to whom they would transfer more in the random matching part of the experiment. Their evidence confirms the sorting hypothesis and gives good reason to assume that not accounting for partner choice may lead to underestimation of the differences in trust towards different types of trustees in other settings as well.

Other experiments have studied partner choice in the ultimatum game (Holm and Engseld 2005; Chiang 2010), the trust game (Bornhorst et al. 2010; Brown et al. 2004; Eckel and Wilson 2000), and the public good game (Coricelli et al. 2004; Page et al. 2005; Barclay and Willer 2007; Sylwester and Roberts 2010, 2013; Aksoy 2015). These studies can be divided into two groups: those investigating the effect of individual differences in, e.g., gender, age, income, social group membership or perceived friendliness on the choice of interaction partners and subsequent cooperative behavior (Bornhorst et al. 2010, Eckel and Wilson 2000, Holm and Engseld 2005, Slonim and Garbarino 2008; Aksoy 2015); and those investigating the effect of partner choice on ex ante cooperative behavior (Brown et al. 2004, Chiang 2010, Coricelli et al. 2004, Page et al. 2005; Barclay and Willer 2007; Sylwester and Roberts 2010, 2013). In other words, this latter set of studies addresses the question of how an oversupply of potential interaction partners induces actors to make competitive commitments to cooperative behavior in order to be selected. This question is mainly studied in the field of behavioral ecology, where it is central to the theories of biological markets (Noë and Hammerstein 1994; Barclay 2013) and competitive altruism (Roberts 1998). Our study mainly contributes to the first strand of this literature.

In the following paragraphs we describe in more detail how we implement partner choice in our experiment, and how we combine it with a random matching condition to elucidate actors' motives behind their partner choices. At the end of the next section we also state our hypotheses. 


\section{Experimental games, design and hypotheses}

\subsection{Experimental games}

Subjects play two different games in our experiment - a standard dictator game (DG) (Forsythe et al. 1994) and a modified version of the investment game (Berg et al. 1995), which we henceforth call the exchange game (EG). In the DG, person $\mathrm{X}$ and person $\mathrm{Y}$ are endowed with $E_{X}$ and $E_{Y}$ Swiss francs (CHF), respectively. Next, person $X$ can decide to give up part or all of their endowment $\left(0 \leq \mathrm{x}_{\mathrm{DG}} \leq \mathrm{E}_{\mathrm{X}}\right)$ and transfer this amount to person $\mathrm{Y}$. The DG ends with person $X$ getting $E_{X}-x_{D G}$ and person $Y$ getting $E_{Y}+x_{D G}$. The DG is nested in the EG. That is, the EG extends the DG by giving person $\mathrm{Y}$ the possibility to make a back transfer; person $\mathrm{Y}$ in the second mover position can decide to give up part of his or her amount $\left(0 \leq \mathrm{y} \leq \mathrm{E}_{\mathrm{Y}}+\mathrm{x}_{\mathrm{EG}}\right)$ and transfer it to person $\mathrm{X}$. Unlike the transfer of person $\mathrm{X}$ in both games, the amount transferred by person $Y$ is tripled. The EG ends with person $X$ getting $E_{X}-x_{E G}+3 y$ and person $Y$ getting $E_{Y}+$ $\mathrm{x}_{\mathrm{EG}}-\mathrm{y} .{ }^{2}$ Given that, in the DG, person $\mathrm{Y}$ does not have the possibility of making a back transfer, person X's transfer $\mathrm{X}_{\mathrm{DG}}$ cannot be motivated by expectations of a back transfer. Moreover, if initial endowments are equal (i.e. $\mathrm{E}_{\mathrm{X}}=\mathrm{E}_{\mathrm{Y}}$ ), person $\mathrm{X}$ 's transfer in the $\mathrm{DG}$ cannot be motivated by inequality aversion (see, e.g., Cox 2004).

\subsection{Experimental design}

We conducted six experimental sessions, with 22 to 26 subjects per session $(N=148$ subjects in total). At the beginning of each session half the subjects were randomly assigned to be a person $\mathrm{X}$ and the other half were assigned to be a person $\mathrm{Y}$; all subjects stayed in their assigned role throughout the experiment. In addition, persons $\mathrm{Y}$ were randomly assigned to one of three conditions. In condition DONPOS (donation possible), a person Y's initial endowment was the same as the endowment of a person $X\left(E_{X}=E_{Y}=C H F\right.$ 16), and the person $Y$ could decide

\footnotetext{
${ }^{2}$ We use this modified version of the investment game, where the second movers' back transfers are multiplied rather than the first movers' transfers, because we want to have more variability in the transfer variable $\mathrm{x}$ and we want to exclude efficiency concerns as a further potential motive for the first mover transfer (Engelmann and Strobel 2004). We call this game an exchange game so as to refer, additionally, to the similar gift exchange games which are widely used to model labor relations.
} 
whether or not to make a donation of CHF 6 to one of three charitable organizations. ${ }^{3}$ They could choose from Amnesty International, the International Committee of the Red Cross, and Médecins Sans Frontières. Thus, a person Y who donated kept CHF 10, and a person Y who did not donate kept CHF 16. Persons Y who were assigned to condition UNEQEND (unequal endowment) or EQEND (equal endowment) did not have the possibility of making a charitable donation. In condition UNEQEND a person $\mathrm{Y}$ was endowed with $\mathrm{CHF} 10\left(\mathrm{E}_{\mathrm{X}}>\mathrm{E}_{\mathrm{Y}}\right)$, and in condition EQEND a person $\mathrm{Y}$ was endowed with $\mathrm{CHF} 16\left(\mathrm{E}_{\mathrm{X}}=\mathrm{E}_{\mathrm{Y}}\right)$. Conditions EQEND and UNEQEND served to study potential endowment effects resulting from persons $\mathrm{Y}$ giving or not giving CHF 6 to charity, respectively. To maximize the number of persons $\mathrm{Y}$ in condition DONPOS, in every session we only assigned one subject each to conditions EQEND and UNEQEND. Thus, our experimental design allowed us to induce four person $\mathrm{Y}$ types in the first stage of each experimental session. Henceforth we will call these four types donor, non-donor, unequally endowed person $\mathrm{Y}$ and equally endowed person $\mathrm{Y}$.

Each experimental session consisted of two parts, the random matching part and the partner choice part, and in condition DONPOS, person $\mathrm{Y}$ had to choose whether or not to make a donation at the beginning of each part. In the random matching part, persons $\mathrm{X}$ had to choose the amount they wanted to transfer to each of the four person Y types, both in the DG and in the EG (see Figure 1). ${ }^{4}$ Persons $\mathrm{X}$ made their eight transfer decisions knowing that at the end of the experiment they would be randomly paired with one person Y, either in the DG or the EG, and that their earnings would be determined based on their actual decisions in this situation. At the same time, persons $\mathrm{Y}$ had to decide upon the amount they wanted to send back to person X. Persons $\mathrm{Y}$ had to specify their back transfers for every possible amount a person $\mathrm{X}$ could transfer to them. This part of the experiment replicates the set-up of our previous study (Fehrler and Przepiorka 2013).

In the partner choice part of the experiment, persons $X$ faced four decision situations (i.e. choice sets), in each of which they were asked to choose one of two interaction partners before they

\footnotetext{
${ }^{3}$ We fixed the amount that could be donated to charity at CHF 6 because that is what we did in our previous study (Fehrler and Przepiorka 2013). The evidence from this previous study allowed us to (correctly) anticipate that we would find at least one donor and one non-donor in each part of the treatment in all sessions.

${ }^{4}$ With regard to donors, persons $\mathrm{X}$ only knew that a donor had made a donation to one of the organizations mentioned above; they did not know to which organization a donor's donation went in particular.
} 
could choose the amount they wanted to transfer to this person (see Figure 2). Persons $\mathrm{X}$ had to choose between a donor and a non-donor, both in the DG and the EG, and between an unequally endowed and an equally endowed person Y, both in the DG and the EG.

Figure 1: Screenshot of random matching part (translated from German)

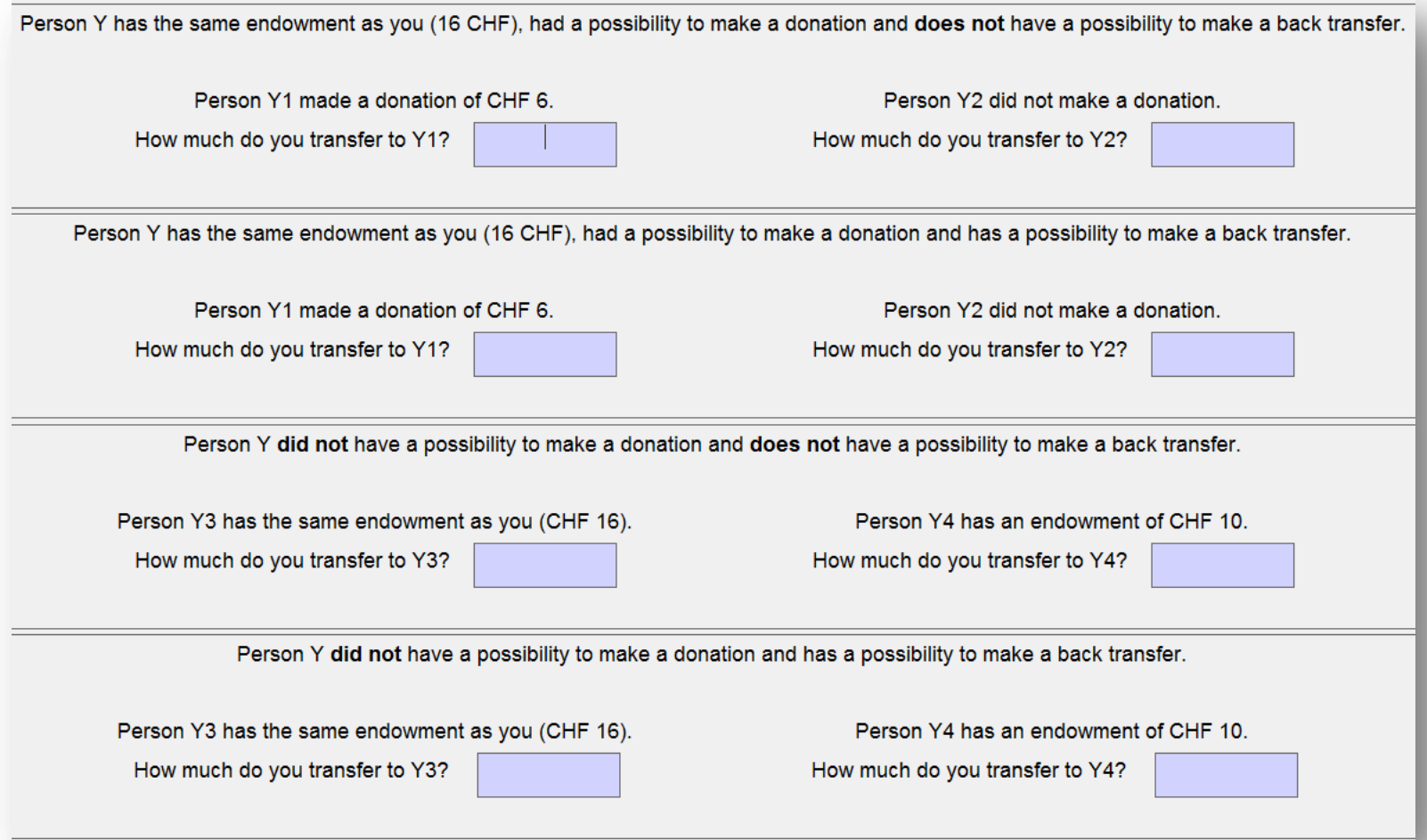

If a person $\mathrm{X}$ was indifferent regarding the two potential interaction partners in any of the four choice sets, they could indicate this, knowing that then one of the two would randomly be chosen as their interaction partner. Persons X made their four partner choices and, conditional on their partner choices, their four transfer decisions, knowing that, at the end of the experiment, they would be randomly assigned to one of the four choice sets and that their earnings would be determined by their actual decisions in this choice set and by the decisions of their partner. Persons $\mathrm{Y}$ faced the same decision situation as was faced in the random matching part. $^{5}$

\footnotetext{
${ }^{5}$ Technically, partner choice was implemented as follows: for a person $\mathrm{Y}$ type selected by a person $\mathrm{X}$ in the randomly selected choice set, the program searched all persons $\mathrm{Y}$ until it found one of that type. The decisions of
} 
Figure 2: Screenshot of partner choice part (translated from German)

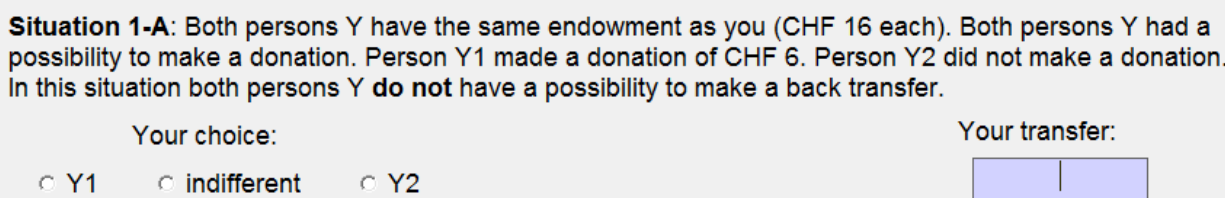

Situation 1-B: Both persons $Y$ have the same endowment as you (CHF 16 each). Both persons $Y$ had a possibility to make a donation. Person $\mathrm{Y} 1$ made a donation of $\mathrm{CHF} 6$. Person $\mathrm{Y} 2$ did not make a donation. In this situation both persons $Y$ have a possibility to make a back transfer.

Your choice:

Your transfer:

$\sim \mathrm{Y} 1 \quad \sim$ indifferent $\sim \mathrm{Y} 2$

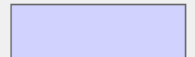

Situation 2-A: Person $Y 3$ has the same endowment as you (16 CHF) and Person $Y 4$ has an endowment of $\mathrm{CHF}$ 10. Both persons $Y$ did not have a possibility to make a donation. In this situation both persons $Y$ do not have a possibility to make a back transfer.

Your choice:

Your transfer:

$\sim Y 3 \quad \sim$ indifferent $\sim Y 4$

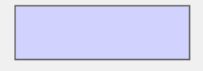

Situation 2-B: Person $\mathrm{Y} 3$ has the same endowment as you (16 CHF) and Person $\mathrm{Y} 4$ has an endowment of $\mathrm{CHF}$ 10. Both persons $Y$ did not have a possibility to make a donation. In this situation both persons $Y$ have a possibility to make a back transfer.

Your choice:

$\sim$ Y3 $\sim$ indifferent $\sim$ Y4

Your transfer:

We varied the sequence of the two parts across experimental sessions. In sessions 1, 2 and 5, subjects decided first in the partner choice part and thereafter in the random matching part, and vice versa in sessions 3, 4 and 6. Finally, we asked persons $X$ to state their expectations regarding person Y's back transfer in the EG, but we did so only once, at the end of the experiment. We asked them to state their expectations for each of the four person Y types making hypothetical transfers of $\mathrm{CHF} 0,8$, and 16 . We chose not to incentivize belief elicitation in order not to further complicate the instructions. Subjects received feedback regarding choices and payoffs from both parts after the belief elicitation stage. The entire experimental set-up was presented to subjects before the experiment started. ${ }^{6}$

that person $\mathrm{Y}$ in the game of that choice set, together with the decisions of person $\mathrm{X}$, determined the payoff for person $\mathrm{X}$. To determine the payoff of a person $\mathrm{Y}$, the program randomly paired the person $\mathrm{Y}$ with a person $\mathrm{X}$, whose decisions in the randomly selected game, together with the decisions of the person Y, determined person Y's payoff. In cases where the randomly selected person $X$ chose a different $Y$ type, person $Y$ received only the endowment.

${ }^{6}$ More details on the experimental procedures and the experimental instructions, including screen-shots of all decision situations, can be found in the online appendix. 


\subsection{Hypotheses}

Since the random matching part of this experiment replicates our previous study (Fehrler and Przepiorka 2013), we expect to find similar results regarding transfers and beliefs.

H1a: Both in the DG and the EG larger amounts will be transferred to donors than to non-donors.

H1b: In the DG, larger amounts will be transferred to unequally endowed person $Y$ types than to equally endowed person $Y$ types, whereas in the EG larger amounts will be transferred to equally endowed person $Y$ types than to unequally endowed person Y types.

H2a: In the EG, donors will be expected to make larger back transfers than nondonors.

H2b: In the EG, equally endowed person $Y$ types will be expected to make larger back transfers than unequally endowed person Y types.

Slonim and Garbarino (2008) present evidence supporting their sorting hypothesis, which states that subjects who receive higher average transfers in a random matching condition will be chosen more often in a partner choice condition. Based on the findings from our previous experiment, and thus consistent with our hypotheses H1a and H1b, we state our corresponding hypotheses regarding partner choice:

H3a: Both in the DG and the EG, donors will be chosen more often as interaction partners than non-donors.

H3b: In the DG, unequally endowed person $Y$ types will be chosen more often as interaction partners than equally endowed person $Y$ types, whereas in the EG equally endowed person $Y$ types will be chosen more often as interaction partners than unequally endowed person $Y$ types.

If subjects in the partner choice part of the experiment indeed choose the partner to whom they want to transfer more, this will have the following effect on average after-choice transfers (see also Slonim and Garbarino 2008): 
H4: Average transfers after partner choice will be higher than average transfers in the random matching part of the experiment.

Finally, and in line with previous studies' findings (see above), we hypothesize that donors will indeed be more trustworthy.

H5: Donors will make larger back transfers than non-donors in the EG (conditional on the transfer they receive).

In addition to testing these hypotheses we explore the motives for partner choices and transfers using regression models. Taken together our analyses will allow us to test our hypotheses and to answer the question whether charitable giving can work as a signal of trustworthiness in order to attract partners for social exchange. We start with an analysis of person $\mathrm{X}$ behavior in the random matching part of the experiment.

\section{Results}

\subsection{Trust and other motives in the random matching part of the experiment}

Figure 3a shows average person $\mathrm{X}$ transfers across games and person $\mathrm{Y}$ types in the random matching part of the experiment, and largely replicates the findings reported in Fehrler and Przepiorka (2013). In line with hypothesis H1a, the figure shows that donors receive significantly higher transfers than non-donors, both in the DG and the EG. Moreover, the transfer difference between donors and non-donors is significantly larger in the EG than in the DG $(t=$ $5.28, p<0.001)$. This suggests that donors receive higher transfers in the EG because they are

trusted more, but also because of other-regarding motives (see also Fehrler and Przepiorka 2013). 
Figure 3: Person $\mathrm{X}$ transfers in the random matching (a) and the partner choice part (b) of the experiment
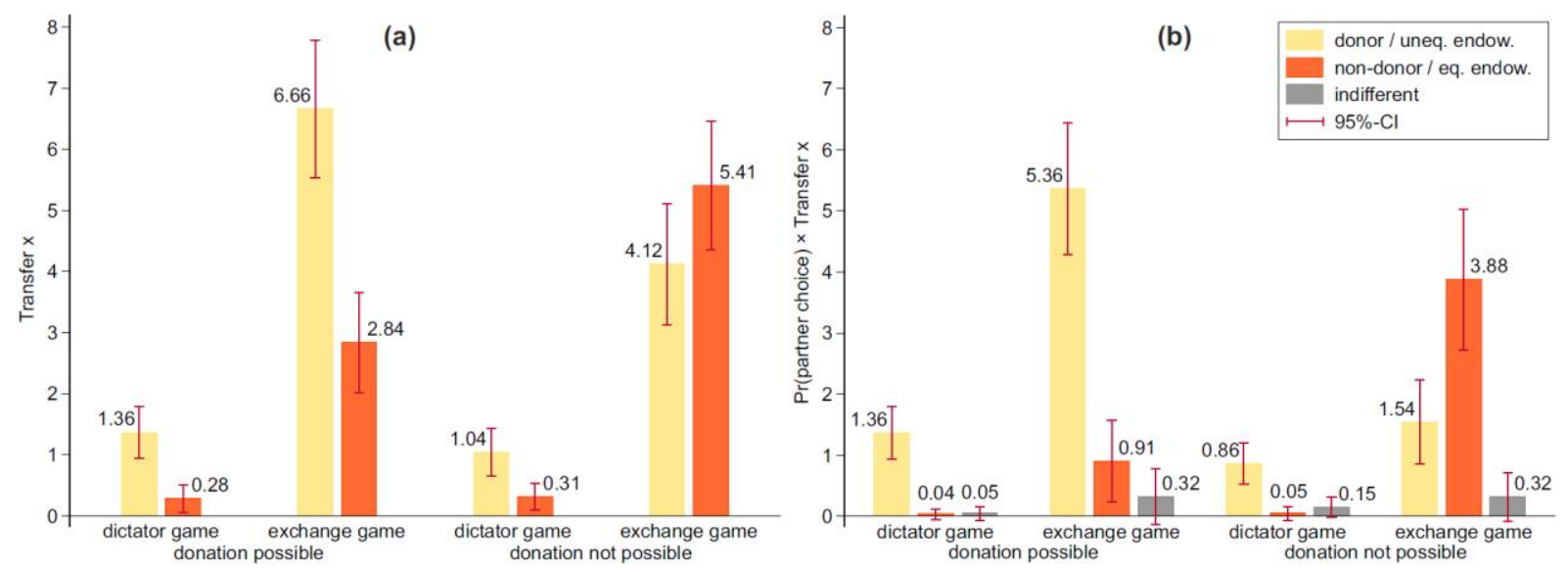

In line with hypothesis $\mathrm{H} 1 \mathrm{~b}$, unequally endowed person $\mathrm{Y}$ types, who start with the same low endowment as donors but without having made a charitable donation (condition UNEQEND), receive significantly higher transfers in the DG than equally endowed person Y types (condition $E Q E N D$ ) (Figure 3a: 1.04 vs. $0.31 ; t=4.98, p<0.001$ ). This finding suggests that some person $\mathrm{X}$ subjects are inequality averse and transfer more to donors than to non-donors because donors have less after having made a donation. However, the difference in DG transfers to donors and non-donors is larger than the difference in DG transfers to unequally and equally endowed person $\mathrm{Y}$ types. Although this difference in differences is relatively small, it is statistically significant (Figure 3a: $1.36-0.28$ vs. $1.04-0.31 ; t=2.12, p=0.038$ ). This result indicates that some person $\mathrm{X}$ subjects (indirectly) reciprocate the good deeds of the donors. However, by far the strongest motive behind person $X$ EG transfers seems to be trust (i.e. expected trustworthiness). This is substantiated by the higher EG transfers, as compared to DG transfers (Figure 3a), and person $\mathrm{X}$ subjects' stated beliefs about the different person $\mathrm{Y}$ types' back transfers (Figure 4). In line with hypotheses $\mathrm{H} 2 \mathrm{a}$ and $\mathrm{H} 2 \mathrm{~b}$, respectively, person $\mathrm{X}$ subjects expect to receive back significantly more from donors than from non-donors, and they expect to receive back significantly more from equally endowed person $\mathrm{Y}$ types than from unequally endowed person Y types (Figure 4). 
Figure 4: Person $\mathrm{X}$ beliefs about person $\mathrm{Y}$ (tripled) back transfers in the EG

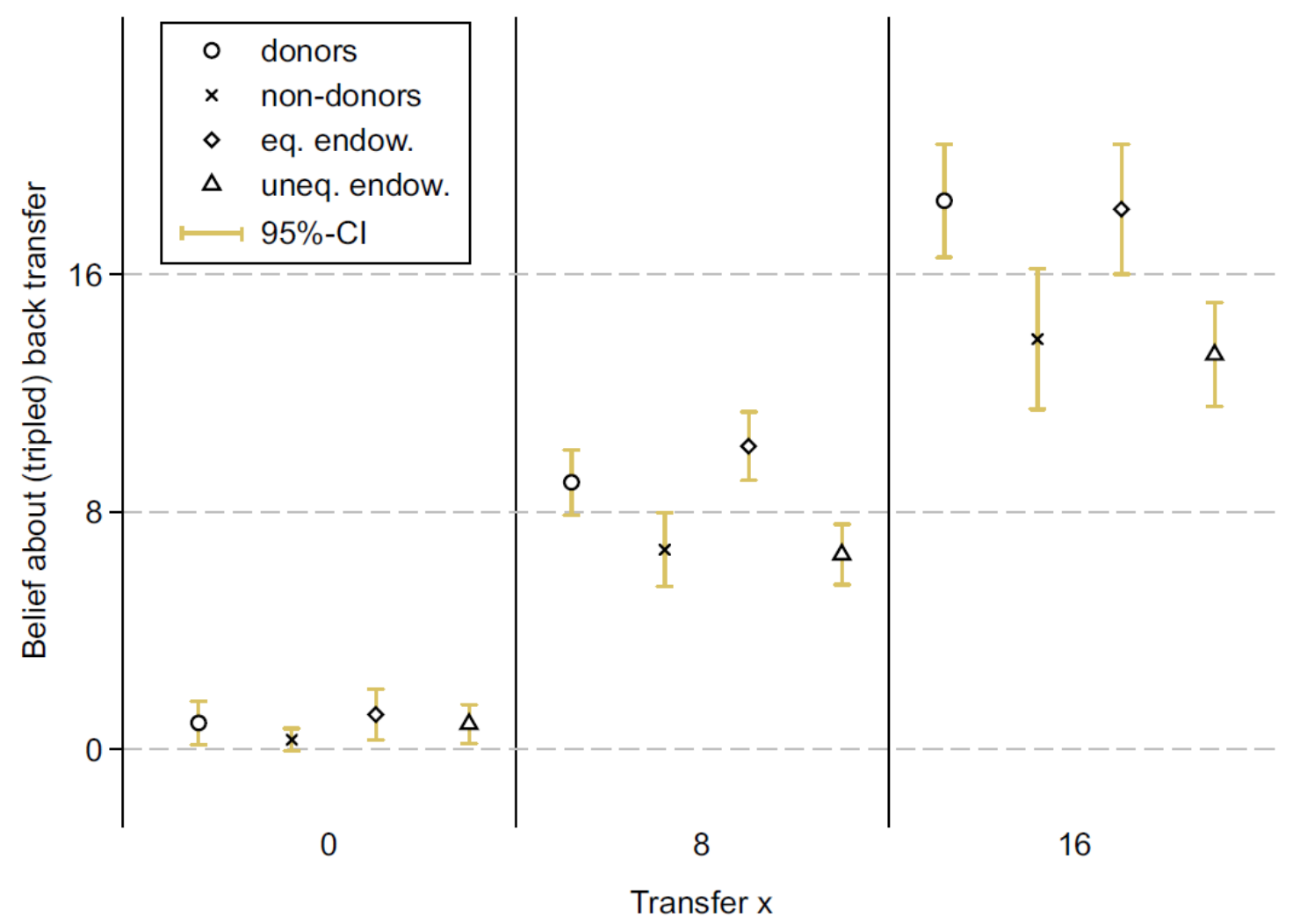

Although person $\mathrm{X}$ subjects do not expect to receive back more from donors than from equally endowed person $\mathrm{Y}$ types, and they do not expect to receive back more from unequally endowed person $\mathrm{Y}$ types than from non-donors, person $\mathrm{X}$ subjects transfer significantly more to donors (6.66 vs. $5.41, t=2.74, p=0.008)$ and unequally endowed person $\mathrm{Y}$ types (4.12 vs. $2.84, t=$ $2.88, p=0.005)$ than to equally endowed person $\mathrm{Y}$ types and non-donors, respectively. This discrepancy between person $\mathrm{X}$ beliefs and transfers can be attributed to person X's otherregarding preferences. If we calculate the same two differences in EG transfers net of the corresponding DG transfers (see Figure 3a) then these differences become statistically insignificant $(6.66-1.36$ vs. $5.41-0.31, t=0.45, p=0.657$ and $4.12-1.04$ vs. $2.84-0.28, t=$ $1.18, p=0.242$, respectively). 


\subsection{Partner choice part of experiment, and comparison}

Table 1: Choice frequencies (in \%) and average transfers across games in the partner choice part of the experiment

\begin{tabular}{|c|c|c|c|}
\hline & & DG & EG \\
\hline & & Choice set 1 & Choice set 2 \\
\hline \multirow[t]{2}{*}{ Donor } & Choice & $54.05(5.83)$ & $81.08(4.58)$ \\
\hline & Transfer & $2.53(0.31)$ & $6.62(0.57)$ \\
\hline \multirow[t]{2}{*}{ Non-donor } & Choice & $8.11(3.19)$ & $14.86(4.16)$ \\
\hline & Transfer & $0.5(0.47)$ & $6.09(1.56)$ \\
\hline \multirow[t]{3}{*}{ Indifferent } & Choice & $37.84(5.68)$ & $4.05(2.31)$ \\
\hline & Transfer & $0.14(0.14)$ & $8.00(3.35)$ \\
\hline & & Choice set 3 & Choice set 4 \\
\hline \multirow[t]{2}{*}{ Uneq. Endow. } & Choice & $40.54(5.74)$ & $29.73(5.34)$ \\
\hline & Transfer & $2.13(0.31)$ & $5.18(0.74)$ \\
\hline \multirow[t]{2}{*}{ Eq. endow. } & Choice & $8.11(3.19)$ & $58.11(5.77)$ \\
\hline & Transfer & $0.67(0.62)$ & $6.67(0.78)$ \\
\hline \multirow[t]{2}{*}{ Indifferent } & Choice & $51.35(5.85)$ & $12.16(3.83)$ \\
\hline & Transfer & $0.29(0.17)$ & $2.67(1.41)$ \\
\hline $\begin{array}{l}\text { Notes: The table lis } \\
\text { to the different pers } \\
\left(N_{1}=888, N_{2}=74\right) \\
\text { subjects). Cluster ro } \\
\text { after choice and per } \\
\text { regarding two perso }\end{array}$ & $\begin{array}{l}\text { ive partner } c \\
\text { ypes in the } D\end{array}$ & $\begin{array}{l}\text { ncies and averag } \\
\text { G in the partner }\end{array}$ & $\begin{array}{l}\text { X transfers (in } \mathrm{CH} \\
\text { Irt of the experime } \\
\text { mber of clusters }(\mathrm{i} \\
\text { are average transfe } \\
\text { they were indiffere }\end{array}$ \\
\hline
\end{tabular}

Figure $3 \mathrm{~b}$ shows average person $\mathrm{X}$ transfers across games and person $\mathrm{Y}$ types weighted by the proportion of partner choices in each of the four choice sets. These numbers result from multiplying the relative choice frequencies of person $\mathrm{Y}$ types with the corresponding average person $\mathrm{X}$ transfers to these person $\mathrm{Y}$ types after choice. In Figure $3 \mathrm{~b}$ we show weighted rather than unweighted person $\mathrm{X}$ transfers because weighted transfers approximate what the different person $\mathrm{Y}$ types receive in expectation if partner choice is possible. ${ }^{7}$ In what follows, we will call the person $\mathrm{X}$ transfers in the random matching condition transfers, and the weighted person $\mathrm{X}$ transfers in the partner choice condition expected transfers. Columns three and four in Table 1

\footnotetext{
${ }^{7}$ This is not exactly equal to the expected value of what they receive because we report the "indifferent" choices as a separate category. Attributing the expected transfers of this category to the other two categories in each choice set would change very little, as they are so low.
} 
report the proportions of partner choices and unweighted person $\mathrm{X}$ transfers after choice separately. ${ }^{8}$

Comparing the numbers in Figure $3 \mathrm{a}$ and the relative choice frequencies in Table 1 reveals that the same person $\mathrm{Y}$ types who receive higher transfers in the random matching part of the experiment are selected far more often as partners in the partner choice part. This is true for all games and choice sets, which supports our hypotheses H3a and H3b. A look at Figure 3 further reveals that the same person $\mathrm{Y}$ types who receive higher transfers in the random matching part of the experiment (Figure 3a) also receive higher expected transfers in the partner choice part (Figure 3b). However, in the partner choice part, differences in expected transfers across person Y types are more pronounced. For example, while in the random matching part donors receive 2.3 times higher EG transfers than non-donors, in the partner choice part expected EG transfers to donors are 5.9 times higher than those to non-donors. The numbers in Table 1 make clear that these larger differences result from the different selection rates and not from differences in afterchoice transfers.

Note that transfers in the random matching part of the experiment (Figure 3a) are higher than expected transfers in the partner choice part (Figure 3b). The reason for this is that in the random matching part the transfers are not weighted by a selection probability, whereas in the partner choice part they are. To compare the differences in transfers in the random matching part $\left(\delta_{1}\right)$ with the differences in expected transfers in the partner choice part $\left(\delta_{2}\right)$, we construct two hypothetical scenarios that are slightly different from our experimental implementation.

In both scenarios there is one person $\mathrm{X}$ and two potential partners $\mathrm{Y}$. In the random matching scenario, one of the potential partners is randomly selected and matched with person $\mathrm{X}$ before the transfer is made; in the partner choice scenario, person $\mathrm{X}$ chooses one partner $\mathrm{Y}$ and there is no "indifferent" option. In the random matching scenario both potential partners Y have the same selection probability of 0.5 . Hence, the selection probabilities of the two partners $\mathrm{Y}$ add up to one in both scenarios.

\footnotetext{
${ }^{8}$ In Table $\mathrm{A} 1$ in the online appendix we report the average transfers to those person $\mathrm{Y}$ types that the person $\mathrm{X}$ subjects chose in the partner choice part, and average transfers to those person $\mathrm{Y}$ types that the person $\mathrm{X}$ subjects did not choose in the partner choice part.
} 
To compute the differences in expected transfers in the two hypothetical scenarios we make the following assumption for the random matching scenario: we assume that person $\mathrm{X}$ transfers would have been the same as in the random matching part of our experiment, in which every person $\mathrm{X}$ made a transfer to each person $\mathrm{Y}$ type. We can then multiply all transfers by 0.5 , thereby also cutting the difference in half $\left(\delta_{1} / 2\right)$. Recall that $\delta_{2}$ results from taking the difference between transfers that were already multiplied with the corresponding empirical selection probabilities. Furthermore, we add the transfers that were made after the choice "indifferent" in the partner choice part in equal proportions to the transfers made after the other two choice options. Note, however, that these transfers cancel out when we compute the difference $\delta_{2}$.

The third column in Table 2 shows the difference between these differences. The table clearly shows that relative to non-donors, donors do significantly better with partner choice than with random matching in both the DG and the EG. Unequally endowed person Y types also do better with partner choice in the DG, and the same is true for equally endowed person Y types in the EG.

Table 2: Differences in transfer differences in the random matching and partner choice parts of the experiment

\begin{tabular}{|c|c|c|c|c|}
\hline $\begin{array}{r}\text { Transfer } \\
\text { (weighted with } 1 / 2\end{array}$ & $\begin{array}{l}\text { fferences } \\
\text { random matching) }\end{array}$ & $\begin{array}{l}\text { Differences in } \\
\text { differences }\end{array}$ & Test for $s t$ & ignificance \\
\hline $\begin{array}{c}\delta_{1} / 2 \\
\text { (random matching) }\end{array}$ & $\begin{array}{c}\delta_{2} \\
\text { (partner choice) }\end{array}$ & $\delta_{1} / 2-\delta_{2}$ & $z$ & $p$ \\
\hline DG transfers (to don & - to non-donors) & & & \\
\hline 0.54 & 1.32 & -0.78 & -4.20 & $<0.001$ \\
\hline EG transfers (to don & - to non-donors) & & & \\
\hline 1.91 & 4.46 & -2.55 & -3.47 & 0.001 \\
\hline DG transfers (to une & endow. - to eq. endo & & & \\
\hline 0.36 & 0.81 & -0.45 & -2.83 & 0.005 \\
\hline EG transfers (to unec & ndow. - to eq. endo & & & \\
\hline-0.64 & -2.34 & 1.70 & 2.25 & 0.024 \\
\hline
\end{tabular}

Note: We calculated the differences in differences and the corresponding test statistics as follows: first, we rearranged the data such that all our models could be estimated with the same categorical explanatory variable. Our explanatory variable comprised the 12 categories that result from the combination of the four choice sets and the three possible choices (including "indifferent") within each set (see Figure 1). Second, using our explanatory variable, we estimated three models: (1) a logit with the binary dependent variable indicating the partner (or "indifferent") a subject had chosen in each choice set; (2) an ordinary least squares (OLS) regression with the amount transferred to a subject's chosen partners as the dependent variable; and (3) an OLS regression with the amount a subject transferred to all potential partners in the random matching part as the dependent variable. Third, using the 'suest' command in Stata, we combined the estimates of our three models in one estimation table and estimated their cluster robust standard errors. Fourth, using the "margins" command in Stata we derived the choice probabilities from model estimation (1), multiplied the choice probabilities with the after-choice transfers obtained in model estimation (2) (that is also how we calculated the numbers in Figure $2 b$ ) and subtracted half the transfers obtained in model estimation (3). Finally, based on the estimation table obtained in the previous step, we used linear combinations of the estimates to estimate the transfer difference between person Y types. 
Turning to our next hypothesis (H4), when we look at unweighted person $\mathrm{X}$ transfers we find that, on average, our results confirm the findings of Slonim and Garbarino's (2008) online experiment. In the EG, average transfers are significantly higher in the partner choice part of the experiment than in the random matching part $(6.17$ vs. $4.76, z=3.68, p<0.001)$. In the DG too, average transfers are significantly higher in the partner choice part $(1.26$ vs. $0.75, z=3.55, p<$ 0.001). This is in line with hypothesis H4. Most actors choose certain interaction partners because they want to transfer more to them. We thus conclude, in line with Slonim and Garbarino (2008), that the higher unweighted transfers in the partner choice part of the experiment are due to a sorting effect. However, in the partner choice part of the experiment not all subjects choose as partner the same person $Y$ type to whom they chose to transfer more in the random matching part. In what follows, we call these subjects "switchers."

In the two choice sets in which subjects choose between donors and non-donors (see Figure 2), $4.1 \%$ switch to a different partner or to "indifferent" in the DG, and 8.1\% switch in the EG. In the two choice sets with unequally endowed and equally endowed persons Y $12.2 \%$ switch in the DG and even $27 \%$ switch in the EG. In all four situations, switchers transfer less to their chosen partner than the maximum transfer they make in the random matching part.

Table 3: Switching

\begin{tabular}{lllllllll}
\hline & \multicolumn{2}{c}{$\begin{array}{c}\text { OLS 1 } \\
\text { DG donor / } \\
\text { non-donor }\end{array}$} & \multicolumn{2}{c}{$\begin{array}{c}\text { EG donor / } \\
\text { non-donor }\end{array}$} & \multicolumn{2}{c}{$\begin{array}{c}\text { OLS 3 } \\
\text { DG uneq. / }\end{array}$} & \multicolumn{2}{c}{$\begin{array}{c}\text { OLS 4 } \\
\text { eq. endow. } \\
\text { eq. endow. }\end{array}$} \\
& Coef & SE & Coef & SE & Coef & SE & Coef & SE \\
\hline Switcher & $-1.84^{*}$ & 0.83 & -0.30 & 1.43 & $-2.03 * * *$ & 0.49 & $-2.16^{*}$ & 0.92 \\
Const. & 0.17 & 0.17 & -0.37 & 0.50 & 0.19 & 0.14 & 0.26 & 0.48 \\
\hline$N$ & 74 & & 74 & & 74 & & 74 & \\
$R^{2}$ & 0.06 & & $<0.01$ & & 0.19 & & 0.07 & \\
\hline
\end{tabular}

Notes: The table lists coefficient estimates and standard errors from OLS regression models where the dependent variable is the difference between the transfer to the selected partner under partner choice and the highest transfer (of the subject) to either of the two potential partners in the same game under random matching (*** $p<0.001, * * p<0.01, * p<0.05$; for two-sided tests). Each model is for one of the four choice sets. The variable "Switcher" indicates if a subject chose a different partner in the partner choice part than the one to whom she transferred more in the random matching part. It is zero if the subject transferred the same amount to both potential recipients under random matching or chose the partner to whom she transferred more under random matching.

Table 3 reports regressions with the difference between the unweighted transfer in the partner choice part of the experiment and the maximum transfer in the random matching part as the dependent variable. The explanatory variable is a dummy variable indicating whether 
a subject chose a different person $Y$ type in the partner choice part than that to whom they transferred more in the random matching part (i.e. an indicator for "switchers"). The negative coefficient estimates range from -0.3 to -2.16 and are statistically significant, except in the EG with a donor vs non-donor choice. An explanation for this behavior might be that switchers want to transfer little and, therefore, switch to partners to whom they feel morally less obliged to give (DellaVigna et al., 2012). For non-switchers, the same transfer difference is much smaller and is statistically not significantly different from zero (see the intercepts in Table 3). The switching rate is highest for the choice between unequally and equally endowed persons $\mathrm{Y}$ in the EG. Like donors, unequally endowed persons $\mathrm{Y}$ receive higher transfers in the DG (Figure 3). However, most subjects believe that they are less trustworthy than equally endowed persons $\mathrm{Y}$, and that a transfer to them would not pay off (Figure 4). This is not the case for donors as compared to non-donors. Hence, a substantial number of subjects who give more to unequally endowed persons Y under random matching, where they cannot avoid this interaction partner, avoid them in the partner choice part. ${ }^{9}$ As a consequence, the switching rate is highest in this choice set.

Most subjects do, however, choose the person $\mathrm{Y}$ type to whom they transfer more in the random matching part of the experiment. This prompts the question whether the same motives that explain transfer differences in the random matching part will also explain partner choices. We address this question next.

\subsection{What explains partner choices and transfers in the EG?}

First, to explain choices, we estimate linear probability models (LPMs), with the binary dependent variable being 1 if the subject chose a donor (rather than a non-donor or "indifferent") in choice set 2 or an unequally endowed person $\mathrm{Y}$ (rather than an equally endowed person $\mathrm{Y}$ or "indifferent") in choice set 4, and zero otherwise (see Figure 2). As our explanatory variables we use dummies for the choice sets, the difference in DG transfers to the corresponding person $Y$ types in the random matching part ( $\triangle \mathrm{DG}$ trans.), and the difference in person $\mathrm{X}$ beliefs about the

\footnotetext{
${ }^{9}$ We also observe a few switches in the other direction. These switchers transfer less to unequally endowed subjects in the random matching part but choose them in the partner choice part.
} 
corresponding person $Y$ types' back transfers ( $\Delta$ Beliefs). ${ }^{10}$ The difference in DG transfers serves as a proxy for inequality aversion and indirect reciprocity, which can influence behavior in both games, and the difference in beliefs about back transfers can be conceived of as a measure for the difference in expected trustworthiness (i.e. trust). We interact $\Delta$ DG trans. and $\Delta$ Beliefs with the choice set dummies and estimate the models without an intercept. This approach is equivalent to estimating separate models for each of the two choice sets, but allows us to test differences in coefficients between choice sets. It should be kept in mind, however, that beliefs and DG transfers are not treatment variables in the experiment. Thus, the results that we report in this section can only be suggestive of causal relations.

For our analysis we use LPMs. It has been shown that logit and probit can produce biased coefficient estimates if the model omits explanatory factors, even if these are uncorrelated with the regressors (Mood 2010; Yatchew and Griliches 1985). LPMs do not rely on the above assumption and, in this regard, are less prone to produce biased coefficient estimates. Moreover, an LPM coefficient can be directly interpreted as the change in probability points due to a oneunit change in the value of the explanatory variable (Angrist and Pischke 2009: 94-107). We also derive (marginal) probabilities from logistic and multinomial logistic regression models using the same explanatory variables as in the LPMs. In the multinomial logistic regression we include "indifferent" as the third response category in our dependent variable (partner choice). Both the estimations of these additional models and the predicted probabilities are presented in the online appendix in tables A2 and A4, and A3 and A5, respectively. Since the LPM coefficient estimates do not differ substantially from the predicted probabilities in tables A3 and A5, we proceed with interpreting the LPMs.

Model LPM 1 in Table 4 distinguishes only the two situations in which person X subjects could choose an interaction partner in the EG. The estimates show that in choice set 2, subjects choose donors in $81 \%$ of the cases, whereas in choice set 4 they choose person $\mathrm{Y}$ subjects with an unequal endowment in less than $30 \%$ of the cases. This result suggests that the positive effect of

\footnotetext{
${ }^{10}$ For hypothetical transfers of CHF 0,8 , and 16, we asked person X subjects what they expected to be transferred back by each of the four person Y types. A person X subject's average belief with regard to a particular person $\mathrm{Y}$ type is the average ratio of expected back transfers to hypothetical transfers multiplied by three. Since the ratio is not defined for the hypothetical transfer CHF 0, the average is only calculated based on the ratios for the hypothetical transfers of CHF 8 and 16. Since the back transfers in the EG are tripled, the average ratio is multiplied by three [i.e., $3\left(b_{8} / 8+b_{16} / 16\right) / 2$ ]. See the notes to Table 4 for further details.
} 
being a donor by far offsets the negative effect of having less than a non-donor to send back in the EG. This difference can partly be explained with subjects' beliefs. Subjects are considerably more likely to choose a donor in choice set 2 if their difference in beliefs about the donor's and non-donor's trustworthiness increases in favor of the donor (LPM 2). In choice set 4, belief differences do not seem to matter for subjects' choices as the coefficient for $\Delta$ Beliefs is statistically insignificant. What is related to partner choices in choice set 4 , though, is the difference in DG transfers. This can be seen in LPM 3, where a CHF 1 increase in $\triangle$ DG trans. is associated with a 9.6 percentage point increase in the probability of an unequally endowed person Y being selected. These effects remain substantially the same when combined in LPM 4. Beliefs about trustworthiness are important in subjects' choices of donors (vs. non-donors and indifferent) but not in their choices of unequally endowed person Y types (vs. equally endowed types and indifferent). At the same time, we find that other motives influence the choice of unequally endowed types (as indicated by the significant effect of $\Delta$ DG trans. in choice set 4) but do not seem to matter for subjects' choices of donors.

Table 4: LPMs of person X EG partner choices

\begin{tabular}{|c|c|c|c|c|c|c|c|c|}
\hline & \multicolumn{2}{|c|}{ LPM 1} & \multicolumn{2}{|c|}{ LPM 2} & \multicolumn{2}{|c|}{ LPM 3} & \multicolumn{2}{|c|}{ LPM 4} \\
\hline & Coef & SE & Coef & SE & Coef & SE & Coef & SE \\
\hline \multicolumn{9}{|c|}{ Choice set $2($ chose donor $=1)$} \\
\hline Const. & $0.811 * * *$ & 0.046 & $0.757 * * *$ & 0.056 & $0.803 * * *$ & 0.056 & $0.747 * * *$ & 0.064 \\
\hline$\Delta$ Beliefs & & & $0.187 * *$ & 0.061 & & & $0.187 * *$ & 0.061 \\
\hline$\Delta \mathrm{DG}$ trans. & & & & & 0.007 & 0.026 & 0.010 & 0.026 \\
\hline \multicolumn{9}{|c|}{ Choice set 4 (chose uneq. endow. $=1$ ) } \\
\hline Const. & $0.297 * * *$ & 0.054 & $0.356^{* * *}$ & 0.073 & $0.228 * * *$ & 0.058 & $0.282 * * *$ & 0.075 \\
\hline$\Delta$ Beliefs & & & 0.155 & 0.118 & & & 0.136 & 0.110 \\
\hline$\Delta \mathrm{DG}$ trans. & & & & & $0.096^{*}$ & 0.040 & $0.092 *$ & 0.041 \\
\hline$N_{1}$ & 148 & & 148 & & 148 & & 148 & \\
\hline$N_{2}$ & 74 & & 74 & & 74 & & 74 & \\
\hline $\operatorname{adj} \cdot R^{2}$ & 0.26 & & 0.29 & & 0.28 & & 0.31 & \\
\hline \multicolumn{9}{|c|}{$\begin{array}{l}\text { Notes: The table lists coefficient estimates and cluster robust standard errors from LPMs }(* * * p<0.001, * * p<0.01, * p \\
<0.05 \text {; for two-sided tests). The binary dependent variable is } 1 \text { if the subject chose a donor or a person Y with an unequal } \\
\text { endowment as their interaction partner in the EG, and is zero otherwise. The variable } \Delta \text { Beliefs is the difference in the } \\
\text { average ratios of expected back transfers to hypothetical transfers the subject had stated having in choice sets } 2 \text { and } 4 \text { and } \\
\text { ranges from }-1.69 \text { to } 2.25 \text {, with mean }=-0.05 \text { and median }=-0.14 \text { (also see footnote } 10 \text { ). The variable } \Delta \text { DG trans. is the } \\
\text { difference in money transfers the subject made in the DG to the corresponding person Y types in the random matching } \\
\text { part and ranges from } 0 \text { to } 6 \text {, with mean }=0.91 \text { and median }=0 . N_{1} \text { denotes the number of decisions and } N_{2} \text { denotes the } \\
\text { number of clusters (i.e. subjects). The adjusted } R^{2} \text { statistics are estimated based on model specifications that include one } \\
\text { intercept. }\end{array}$} \\
\hline
\end{tabular}


We now turn to EG transfers. To explain transfers in the random matching part of the experiment we regress EG transfers on DG transfers and on beliefs about trustworthiness (Table 5, OLS 1 and 2). For the partner choice part, the dependent variable is the unweighted EG transfer made to the chosen trustee. The explanatory variables are the DG transfers to the same type of partner in the random matching part of the experiment and the belief about the trustworthiness of the partner (Table 5, OLS 3 and 4). Assuming that the effects of the different motives are the same across situations, we would expect beliefs and DG transfers to explain most of the variation in EG transfers, independent of the decision situation (i.e. choice set) or person $Y$ type. We therefore pool the decision situations in models OLS 1 and 3. In addition, we report estimates for less restricted models in which all person Y types are treated separately (OLS 2 and 4).

The variation in the coefficients of Beliefs and DG trans. across person Y types in OLS 2 and 4 indicates that the motives captured by these variables might carry different weights depending on the person Y type. We use the DG transfer as a proxy for different motives other than beliefs, such as inequity aversion and indirect reciprocity. These motives can play different roles depending on the interaction partner and the game. Furthermore, in the partner choice part, there is self-selection of trustors who are heterogeneous with respect to their beliefs and motives. Trustors choosing non-donors, for example, hold quite different beliefs regarding the trustworthiness of non-donors than trustors choosing donors (see Figure A1 in the online appendix).

The model fits are much better for the random matching part of the experiment (OLS 1 and 2) than for the partner choice part (OLS 3 and 4). Both DG trans. and Beliefs are highly significant in the random matching part and explain a substantial part of the variation in EG transfers (OLS 1). In the partner choice part, these variables explain far less of the variation and only Beliefs remains statistically significant (OLS 3). To some extent, the larger standard errors simply reflect the lower number of observations in the partner choice part, where half as many transfers are made. Moreover, after partner choice, there is also less variation in both the explanatory and the dependent variable. Subjects who are inequity averse, for example, are more likely to select unequally endowed person Y types in the EG (see Table 4), and they make larger DG transfers to unequally endowed person $\mathrm{Y}$ types in the random matching part. Consequently, the variation in both the explanatory variable DG trans. and the outcome variable (i.e. after-choice EG transfers) 
will be smaller within each person Y. As can be seen in Table 1, the variation in the outcome variables has also become smaller between person $\mathrm{Y}$ types in choice set 2 (donors vs. nondonors), which suggests that motives captured in the DG transfers that influence both partner choices and transfers in the random matching part, do not influence after-choice transfers in the same way.

Table 5: OLS regression models of person X EG transfers

\begin{tabular}{|c|c|c|c|c|c|c|c|c|}
\hline & \multicolumn{4}{|c|}{ Random matching part } & \multicolumn{4}{|c|}{ Partner choice part } \\
\hline & \multicolumn{2}{|c|}{ OLS 1} & \multicolumn{2}{|c|}{ OLS 2} & \multicolumn{2}{|c|}{ OLS 3} & \multicolumn{2}{|c|}{ OLS 4} \\
\hline & Coef & SE & Coef & SE & Coef & SE & Coef & SE \\
\hline Constant(s) & $4.254 * * *$ & 0.380 & & & $6.069 * * *$ & 0.582 & & \\
\hline Donor & & & $4.964 * * *$ & 0.586 & & & $5.920 * * *$ & 0.728 \\
\hline Non-donor & & & $3.094 * * *$ & 0.474 & & & $5.903 * * *$ & 1.579 \\
\hline Uneq. endow. & & & $4.098 * * *$ & 0.705 & & & $6.235^{* * *}$ & 0.959 \\
\hline Eq. endow. & & & $4.951 * * *$ & 0.514 & & & $6.158 * * *$ & 0.811 \\
\hline Beliefs & $3.024 * * *$ & 0.470 & & & $2.277 * *$ & 0.849 & & \\
\hline$\times$ Donor & & & $3.627 * * *$ & 0.592 & & & 1.260 & 1.155 \\
\hline$\times$ Non-donor & & & $2.552 * * *$ & 0.650 & & & 2.855 & 2.071 \\
\hline$\times$ Uneq. endow. & & & $2.432 *$ & 0.995 & & & 2.577 & 1.423 \\
\hline$\times$ Eq. endow. & & & $2.608 * * *$ & 0.697 & & & $3.205 *$ & 1.395 \\
\hline DG trans. & $0.644 * *$ & 0.202 & & & 0.012 & 0.238 & & \\
\hline$\times$ Donor & & & $0.872 * * *$ & 0.232 & & & 0.398 & 0.241 \\
\hline$\times$ Non-donor & & & 0.421 & 0.283 & & & -0.724 & 0.656 \\
\hline$\times$ Uneq. endow. & & & 0.429 & 0.330 & & & -0.360 & 0.485 \\
\hline$\times$ Eq. endow. & & & -0.276 & 0.391 & & & $-0.939 *$ & 0.418 \\
\hline$N_{1}$ & 296 & & 296 & & 136 & & 136 & \\
\hline$N_{2}$ & 74 & & 74 & & 72 & & 72 & \\
\hline adj. $R^{2}$ & 0.21 & & 0.25 & & 0.05 & & 0.03 & \\
\hline $\begin{array}{l}\text { Notes: The table lists coe } \\
0.05 \text {; for two-sided tests } \\
\text { payback threshold) of ex } \\
0.01 \text { and median }=0.03 \\
\text { random matching part at } \\
\text { number of clusters (i.e. } \\
\text { picked "indifferent" in b } \\
\text { adjusted } R^{2} \text { statistics fo } \\
\text { dummies. }\end{array}$ & $\begin{array}{l}\text { ficient estimat } \\
\text { The depender } \\
\text { pected back tr } \\
\text { also see footn } \\
\text { d ranges from } \\
\text { bjects). Note t } \\
\text { th of the two } \\
\text { OLS } 2 \text { and } 4\end{array}$ & $\begin{array}{l}\text { s and clus } \\
\text { variable } \\
\text { nsfers the } \\
\text { te } 10 \text { ). Th } \\
\text { to } 8 \text {, wit } \\
\text { at the lowe } \\
\text { hoice sets } \\
\text { are estim }\end{array}$ & $\begin{array}{l}\text { bust standar } \\
\text { rson X EG tr } \\
\text { ect had stated } \\
\text { riable DG tra } \\
\text { ean = } 0.75 \text { an } \\
\text { mber of clust } \\
\text { ree (nine) sul } \\
\text { with specific }\end{array}$ & $\begin{array}{l}\text { rrors frol } \\
\text { sfers. Th } \\
\text { laving in } \\
\text { is the } \\
\text { median } \\
\text { s under } p \\
\text { cts picke }\end{array}$ & $\begin{array}{l}S \text { regression } \\
\text { iable Beliefs } \\
\text { ce sets } 2 \text { and } \\
\text { y transfer the } \\
V_{1} \text { denotes the } \\
r \text { choice resul } \\
\text { different" in }\end{array}$ & $\begin{array}{l}\text { odels }(* * \\
\text { the averc } \\
\text { and rang } \\
\text { ubject } m \\
\text { number o } \\
\text { from the } \\
\text { hoice set }\end{array}$ & $\begin{array}{l}<0.001, * * p \\
\text { ratio (centerec } \\
\text { from }-1 \text { to } 2 \text {, } \\
\text { in choice set } \\
\text { ecisions and } \\
\text { clusion of two } \\
\text { 4) lowering } N\end{array}$ & $\begin{array}{l}0.01, * p \\
\text { at } 1 \text {, i.e. the } \\
\text { ith mean } \\
\text { or } 3 \text { in the } \\
\text { denotes the } \\
\text { ubjects who } \\
\text { to } 136 \text {. The }\end{array}$ \\
\hline
\end{tabular}

In Section 4.2 we already saw that most of the differences in expected transfers in the partner choice part of the experiment accrue at the partner choice stage and not the transfer stage. The models in Table 4 and models OLS 3 and 4 in Table 5 indicate that trust (i.e. beliefs about back 
transfers) is the most important factor contributing to the higher selection frequency of donors, and consequently their higher expected transfers in the EG.

\subsection{Are donors more trustworthy?}

The next important question is whether donors are indeed more trustworthy than non-donors (hypothesis H5). ${ }^{11}$ Do donors transfer back more in the EG than non-donors? Table 6 lists the estimates from OLS regression models regressing the tripled person Y back transfers on person $\mathrm{X}$ transfers, person $\mathrm{Y}$ donor status and the interaction of these two variables. For the 62 person $\mathrm{Y}$ subjects, who were randomly assigned to condition DONPOS and thus had the possibility of donating, we have two observations for each of the 17 possible transfers $\mathrm{x}$ (CHF 0 through CHF 16) and the donor status - one in the partner choice part and one in the random matching part. This results in $62 \times 17 \times 2=2108$ data points.

Table 6: OLS regression models of person Y back transfers

\begin{tabular}{|c|c|c|c|}
\hline & $\begin{array}{c}\text { OLS 1 } \\
\text { both conditions } \\
\text { pooled }\end{array}$ & $\begin{array}{c}\text { OLS } 2 \\
\text { partner choice } \\
\text { part }\end{array}$ & $\begin{array}{c}\text { OLS 3 } \\
\text { random matching } \\
\text { part }\end{array}$ \\
\hline \multirow[t]{2}{*}{ Transfer $\mathrm{x}$} & $0.712 * * *$ & $0.696 * * *$ & $0.726^{* * *}$ \\
\hline & $(0.105)$ & $(0.150)$ & $(0.103)$ \\
\hline \multirow[t]{2}{*}{ Donor } & 1.094 & 0.727 & 1.596 \\
\hline & $(1.831)$ & (1.849) & $(2.060)$ \\
\hline Transfer $\mathrm{x}$ & 0.185 & 0.185 & 0.193 \\
\hline$\times$ Donor & $(0.152)$ & $(0.183)$ & $(0.183)$ \\
\hline \multirow[t]{2}{*}{ Const. } & $6.239 * * *$ & $6.136 * * *$ & $6.321 * * *$ \\
\hline & $(0.946)$ & $(1.135)$ & $(0.942)$ \\
\hline$N_{1}$ & 2108 & 1054 & 1054 \\
\hline$N_{2}$ & 62 & 62 & 62 \\
\hline$R^{2}$ & 0.18 & 0.18 & 0.18 \\
\hline \multicolumn{4}{|c|}{$\begin{array}{l}\text { Notes: The table lists coefficient estimates and cluster robust standard errors from } \\
\text { OLS regression models (*** p }<0.001, * * \mathrm{p}<0.01, * \mathrm{p}<0.05 \text {; for two-sided tests). } \\
\text { The dependent variable is the tripled person } \mathrm{Y} \text { back transfer in the EG. Transfer } \mathrm{x} \text { is } \\
\text { the person } \mathrm{X} \text { transfer in the EG (ranging from } 0 \text { to } 16 \text { ) centered at } 8 \text {. Donor is a } \\
\text { dummy variable with a value of } 1 \text { if the person } \mathrm{Y} \text { subject had made a donation, and is } \\
\text { zero otherwise. } N_{1} \text { denotes the number of decisions and } N_{2} \text { denotes the number of } \\
\text { clusters (i.e. subjects). }\end{array}$} \\
\hline
\end{tabular}

\footnotetext{
${ }^{11} 58.1 \%$ of all persons $\mathrm{Y}$ in the DONPOS condition choose to donate in the partner choice part and $46.8 \%$ in the random matching part. $66.1 \%$ donate in at least one of the two parts and $38.8 \%$ in both parts. $23.1 \%$ of the donations go to Amnesty International, $29.2 \%$ to the International Committee of the Red Cross, and $47.7 \%$ to Médecins Sans Frontières.
} 
Model OLS 1 in Table 6 shows that the average back transfer of a non-donor for a transfer of CHF 8 (the variable Transfer $\mathrm{x}$ is centered at CHF 8) is CHF 6.24, and the back transfer of a donor is on average CHF 1.09 higher. Moreover, for a CHF 1 increase in Transfer x, a nondonor's back transfer increases by CHF 0.71, while a donor's back transfer increases by CHF 0.90. Although these differences indicate that donors are, on average, more trustworthy than nondonors, the differences are not statistically significant. These results do not change substantially if we estimate the regression model for the partner choice (OLS 2) and the random matching part of the experiment (OLS 3) separately.

Thus far we have found no statistical support for hypothesis H5, that donors are more trustworthy than non-donors. However, there are good reasons to assume that ours is a rather conservative test of this hypothesis. First, note that donors, everything else held constant, have CHF 6 less to send back in the EG than non-donors. In fact, donors transfer back substantially more than non-donors as a fraction of the amount of money they have at their disposal after receiving person $\mathrm{X}$ 's transfer (around 50\% more). So, the fact that the absolute difference in back transfers is not bigger might stem from the relatively large size of the donation. Second, the OLS regression models in Table 6 impose a linearity restriction on the relation between person $\mathrm{X}$ transfers and person $Y$ back transfers. If we estimate an unrestricted model with a full set of dummy variables - one for each possible value of Transfer $\mathrm{x}$ - we find that donors' back transfers are higher than non-donors' back transfers for all transfer levels (except for $\mathrm{x}=6$ ), and the joint test of these 17 differences being a random occurrence yields $F_{17,61}=1.67$, with $p=$ 0.075. . $^{12}$ Although donors tend to be more trustworthy than non-donors, we prefer to draw the more conservative conclusion that donors are neither more nor less trustworthy than non-donors.

Strategic consideration on the part of donors is unable to explain this result as donations do not pay off in monetary terms in either condition. In the partner choice part, the expected EG transfer to a donor is on average CHF 4.46 higher than the transfer to a non-donor, and the corresponding difference is CHF 3.82 in the random matching part (see Figure 3), while the donation always

\footnotetext{
12 This analysis is based on the data from both the partner choice and random matching parts of the experiment. Carrying out the same analysis separately for the two conditions sheds some light on the possible reasons for the statistically insignificant difference between donors and non-donors. In the partner choice part, only 12 of the 17 differences between donors and non-donors are positive, whereas in the random matching part all 17 differences are positive (in which case we get $F_{17,61}=2.32, p=0.009$ ).
} 
costs CHF 6. Recall, moreover, that with probability one half, the DG is selected to determine subjects' payoffs, and in the DG the difference between transfers to donors and non-donors is even smaller (CHF 1.32).

A further indication that signaling is unlikely to be a purely strategic act of self-regarding subjects is provided by an unpublished result from our previous experiment (Fehrler and Przepiorka 2013). There, we elicited trustees' beliefs about trustors' transfers to donors and nondonors. Donors did expect higher transfers to donors than to non-donors in that experiment, but the expected difference (CHF 4.3) was smaller than the cost of the donation (CHF 6).

\subsection{Robustness checks}

Recall that we varied the sequence of the partner choice and random matching parts of the experiment between sessions. To see whether there were any sequence effects we ran all analyses separately for the sessions starting with the partner choice part and the sessions starting with the random matching part. Surprisingly, significantly more people donated in the sessions starting with the random matching part. However, almost no other statistic is statistically different between the sequences. This is true for all transfer and belief levels and all the regression analyses. $^{13}$

Following the suggestion of a referee, we ran an additional treatment as a robustness check of our findings in the EG with partner choice between donors and non-donors. In this treatment, we used the game method rather than the strategy method, and we let subjects interact for 10 rounds. In each round groups of one trustor and two trustees were randomly formed. In the beginning of each round the two trustees had the opportunity to donate, as in the main treatment. Then, trustors learned whether either trustee had donated or not and had to choose one of them as their partner for the EG described in Section 3.1. We find that behavior is very stable over the 10

\footnotetext{
${ }^{13}$ Details of these analyses are omitted here because of the limited space but they can be obtained from the authors upon request. $78.1 \%$ donated at least once in the sessions starting with the random matching part and $53.3 \%$ in the other sessions $(t=2.10, p=0.040)$. The coefficient for Beliefs in OLS 1 (as in Table 5) is significantly smaller in the sessions starting with the partner choice part but still significantly larger than zero (at the 5\% level). Also the coefficient for Beliefs in OLS 3 (as in Table 5) is smaller in the sessions starting with the partner choice part, albeit no longer significantly different from zero. However, given the sheer volume of statistics it is to be expected that a few significant differences will be found in all these comparisons.
} 
rounds and our key findings from the main treatment are confirmed: (i) donors are chosen far more often than non-donors, and are thus partially compensated for their donation; (ii) they do not benefit monetarily from the donation; (iii) there is no statistically significant difference in trustworthiness between donors and non-donors. ${ }^{14}$

\section{Discussion}

Our results suggest that charitable giving can induce perceptions of trustworthiness and trust in potential interaction partners. Donors are believed to be more trustworthy; they are therefore chosen more often as partners in the EG, and they thus receive, in expectation, higher transfers than non-donors. The monetary benefits from signaling are substantially lower than the costs of the donation, making it implausible that strategic considerations are the main driver of charitable giving. However, unlike previous studies, we do not find donors to be significantly more (or less) trustworthy than non-donors. In the following paragraphs we relate our findings to the literature on CSR and electoral competition. Thereafter, we discuss the sorting pattern we observed in our partner choice treatment in more detail.

In the context of firms, it has been argued that CSR can serve as a signal of trustworthiness (e.g. Vlachos et al. 2008). ${ }^{15}$ This view is supported by Elfenbein et al. (2012), who show that product offers under eBay's Giving Works program - where sellers dedicate a fraction of the selling price to a charity - have higher sales and achieve higher selling prices than offers of identical products by the same sellers but without the charity component. Our findings (which, it should be noted, come from a laboratory experiment with student subjects) corroborate their conjecture that it is indeed the higher level of expected trustworthiness of charitable sellers that attracts more buyers and that drives selling prices.

Several papers have discussed the role of pro-social or environmental missions of non-profit organizations and firms in attracting motivated workers (Besley and Ghatak 2005; Brekke and

\footnotetext{
${ }^{14} \mathrm{We}$ present the design and results in more detail in the online appendix.

${ }^{15}$ Of course, there are many other reasons for charitable giving and CSR than signaling trustworthiness. For articles providing an overview of CSR see, e.g., Bénabou and Tirole (2010) and Aguinis and Glavas (2012); for articles on the motives for charity see, e.g., Bénabou and Tirole (2006), Harbaugh et al. (2007), or Popkowski Leszczyc and Rothkopf (2010).
} 
Nyborg 2008; Nyborg and Zhang 2012; Fehrler and Kosfeld 2014). Firms with such missions are likely to be more trustworthy interaction partners for customers as they attract and recruit workers that are motivated by these missions, and evidence shows that people who identify themselves with pro-social missions are more trustworthy and cooperative in trust and public good games (Brekke et al. 2011; Fehrler and Kosfeld 2013). Moreover, CSR investments might have an additional benefit for firms as they might motivate their employees to expend more effort in their work. Several experimental studies have demonstrated that a substantial fraction of subjects exert more effort if this generates a donation to a non-governmental organization (Tonin and Vlassopoulos 2015; Koppel and Regner 2014), and that these subjects self-select into employment contracts that feature such social incentives (Fehrler and Kosfeld 2014). These considerations suggest that firms are likely to differ in their trustworthiness and that signaling their trustworthiness through CSR investments could have additional benefits for trustworthy firms.

Appearing trustworthy also matters in electoral competitions. Conceiving of representatives as trustees and voters as trustors has a long tradition in political science (see Levi and Stoker 2000 for a review). While the early public choice literature, which portrayed politicians as pure opportunists who only pursue their narrow self-regarding interests, did not support the idea that successful candidates might differ in terms of social preferences (see the discussion in Besley 2005), more recent theoretical contributions suggest that candidates with non-selfish preferences or a sense of responsibility or duty toward the country or electorate can be very successful in electoral competitions (Callander and Wilkie 2007; Kartik and McAfee 2007; Callander 2008). Political scientists have long argued that the perceived trustworthiness of candidates is an important factor in elections, and they have presented supportive evidence for this claim. Parker (1989), who analyzes survey data from several American national election studies, finds that trust in their representative is important for the electoral support provided by a substantial fraction of survey respondents. Mondak and Huckfeldt (2006), using survey experiments, show that the trustworthiness of hypothetical politicians strongly influences their evaluations by subjects. In a more recent study, Galeotti and Zizzo (2014) demonstrate that subjects who are more trustworthy in a trust game are elected more often as group representatives in a subsequent laboratory election. The signaling account we present in this paper corroborates the idea that voters' choices of candidates may be influenced by their perception of the candidates' 
trustworthiness. Consistent with this view, recent studies show that individuals who are more generous in regard to charity or in public good games are voted for more often in laboratory elections (Milinski et al. 2002; Hamman et al. 2011). ${ }^{16}$

In addition to illuminating the potential of charitable giving as a signal of trustworthiness, our study also contributes to the literature on partner choice in games and experiments more generally. First, our comparison of the partner choice and the random matching parts of the experiment shows that, while most subjects favor the same groups in both conditions, transfer differences between the (potential) recipient groups turn out to be much starker with partner choice. This suggests that outcome differences between groups of potential interaction partners might be more pronounced in other situations that feature partner choice as well. Second, our sorting hypotheses are mostly supported by the data: interaction partners who receive higher transfers in the random matching part of the experiment are also preferred as interaction partners in the partner choice part. We also observe an increase in average transfers with partner choice as most subjects choose the partner to whom they want to transfer more. Third, pulling results in the opposite direction to the sorting effect (Slonim and Garbarino 2008), some subjects "switch" and choose a different partner and transfer less to that partner in the partner choice part of the experiment than the maximum transfer they make in the random matching part. A possible explanation for this might be that these subjects feel morally obliged to give more to certain interaction partners and so avoid these partners when given the choice.

Despite the important role partner choice plays in many settings, studies of social preferences have so far mainly focused on situations with random matching. Further research both on the role of charity as a signal of trustworthiness - most importantly, replication studies in other settings to establish external validity - and on the role of partner choice in other games and settings is needed to shed more light on these under-researched topics.

\footnotetext{
${ }^{16}$ In US politics the charitable donations of candidates is an issue that receives considerable media attention. One example is the 2012 presidential election. In 2011, Michelle and Barack Obama donated 21.8\% of their income to charity. In the same year, Ann and Mitt Romney gave $29.4 \%$ of their income, while Joe and Jill Biden only gave $1.5 \%$. After these numbers became public in 2012 they were widely discussed in the media (e.g. Politico, 21 September 2012, "Romney 2011 taxes: Mitt gives more to charity than President Obama, Joe Biden", http://www.politico.com/news/stories/0912/81529.html\#ixzz2yaTkPxkG).
} 


\section{Acknowledgements}

We would like to thank Christiane Bozoyan, Diego Gambetta, Tobias Gesche, Ben Jann, Séverine Toussaert, Irenaeus Wolff, two anonymous reviewers, and participants in several conferences and workshops for their insightful comments and suggestions. This research was supported by the Swiss National Science Foundation [grant number 100017_124877]. All remaining errors are our own.

\section{References}

Aguinis, Herman, and Ante Glavas. 2012. What We Know and Don't Know About Corporate Social Responsibility: A Review and Research Agenda. Journal of Management 38:932968.

Albert, Max, Werner Güth, Erich Kirchler, and Boris Maciejovsky. 2007. "Are we nice(r) to nice(r) people? An experimental analysis." Experimental Economics 10:53-69.

Anderhub, Vital, Dirk Engelmann, and Werner Güth. 2002. "An experimental study of the repeated trust game with incomplete information." Journal of Economic Behavior \& Organization 48:197-216.

Angrist, Joshua D., and Jören-Steffan Pischke. 2009. Mostly Harmless Econometrics: An Empiricist's Companion. Princeton (NJ): Princeton University Press.

Ashraf, Nava, Iris Bohnet, and Nikita Piankov. 2006. "Decomposing trust and trustworthiness." Experimental Economics 9:193-208.

Bacharach, Michael, and Diego Gambetta. 2001. "Trust in Signs." Pp. 148-184 in Trust in Society, edited by Karen S. Cook. New York: Russell Sage Foundation.

Bacharach, Michael, Gerardo Guerra, and Daniel J. Zizzo. 2007. "The self-fulfilling property of trust: An experimental study." Theory and Decision 63:349-388.

Barclay, Pat. 2013. "Strategies for cooperation in biological markets, especially for humans." Evolution and Human Behavior 34:164-175.

Barclay, Pat and Robb Willer. 2007. "Partner choice creates competitive altruism in humans." Proceedings of the Royal Society London B 274:749-753.

Battigalli, Pierpaolo, and Dufwenberg, Martin, 2009. Dynamic psychological games. Journal of Economic Theory 144:1-35. 
Bénabou, Roland, and Jean Tirole. 2006. Incentives and prosocial behavior. American Economic Review 96:1652-1678.

—. 2010. "Individual and Corporate Social Responsibility." Economica 77:1-19.

Berg, Joyce, John Dickhaut, and Kevin McCabe. 1995. "Trust, Reciprocity, and Social History." Games and Economic Behavior 10:122-142.

Besley, Timothy (2005). Political selection. Journal of Economic Perspectives 19:43-60.

Besley, Timothy, and Ghatak, Maitreesh, 2005. Competition and Incentives with Motivated Agents. American Economic Review 95:616-636.

Bolle, Friedel, and Jessica Kaehler. 2007. "Introducing a Signaling Institution: An Experimental Investigation." Journal of Institutional and Theoretical Economics 163:428-447.

Bolton, Gary E., Elena Katok, and Axel Ockenfels. 2004a. "How Effective are Electronic Reputation Mechanisms? An Experimental Investigation." Management Science 50:15871602.

—. 2004b. "Trust among Internet Traders." Analyse \& Kritik 26:185-202.

Bornhorst, Fabian, Andrea Ichino, Oliver Kirchkamp, Karl H. Schlag, and Eyal Winter. 2010. "Similarities and differences when building trust: the role of cultures." Experimental Economics 13:260-283.

Bracht, Juergen and Nick Feltovich. 2009. "Whatever you say, your reputation precedes you: Observation and cheap talk in the trust game." Journal of Public Economics 93:1036-1044.

Brekke, Kjell A., Karen E. Hauge, Jo T. Lind, and Karine Nyborg. 2011. "Playing with the good guys. A public good game with endogenous group formation." Journal of Public Economics 95:1111-1118.

Brekke, Kjell A., and Nyborg, Karine. 2008. Attracting responsible employees: Green production as labor market screening. Resource and Energy Economics 30:509-526.

Brown, Martin, Armin Falk, and Ernst Fehr. 2004. "Relational Contracts and the Nature of Market Interactions." Econometrica 72:747-780.

Callander, Steven. 2008. Political Motivations. Review of Economic Studies 75:671-697.

Callander, Steven, and Simon Wilkie. 2007. Lies, damned lies, and political campaigns. Games and Economic Behavior 60:262-286.

Camerer, Colin and Keith Weigelt. 1988. "Experimental Test of a Sequential Equilibrium Reputation Model." Econometrica 56:1-36.

Chiang, Yen-Sheng. 2010. "Self-interested partner selection can lead to the emergence of fairness." Evolution and Human Behavior 31:265-270. 
Coricelli, Giorgio, Dietmar Fehr, and Gerlinde Fellner. 2004. "Partner Selection in Public Goods Experiments." Journal of Conflict Resolution 48:356-378.

Cox, James C. 2004. "How to identify trust and reciprocity." Games and Economic Behavior 46:260-281.

DellaVigna, S., J. a. List, and U. Malmendier. 2012. "Testing for Altruism and Social Pressure in Charitable Giving." The Quarterly Journal of Economics 127: 1-56.

Eckel, Catherine C. and Rick K. Wilson. 2000. "Whom to trust? Choice of partner in a trust game." Working paper, Virginia Tech and Rice University.

Elfenbein, Daniel W., Ray Fisman, and Brian Mcmanus. 2012. "Charity as a Substitute for Reputation: Evidence from an Online Marketplace." Review of Economic Studies 79:14411468.

Engelmann, Dirk, and Strobel, Martin. 2004. Inequality aversion, efficiency, and maximin preferences in simple distribution experiments. The American Economic Review 96:19061911.

Fehr, Ernst. 2009. "On The Economics and Biology of Trust." Journal of the European Economic Association 7:235-266.

Fehr, Ernst and Klaus M. Schmidt. 1999. "A Theory of Fairness, Competition, and Cooperation." Quarterly Journal of Economics 114:817-868.

Fehrler, Sebastian, and Michael Kosfeld. 2013. Can you trust the good guys? Trust within and between groups with different missions. Economics Letters 121:400-404.

Fehrler, Sebastian, and Michael Kosfeld. 2014. Pro-social missions and worker motivation: An experimental study. Journal of Economic Behavior \& Organization 100:99-110.

Fehrler, Sebastian and Wojtek Przepiorka. 2013. "Charitable giving as a signal of trustworthiness: Disentangling the signaling benefits of altruistic acts." Evolution and Human Behavior 34:139-145.

Forsythe, Robert, Joel L. Horowitz, N. E. Savin, and Martin Sefton. 1994. "Fairness in Simple Bargaining Experiments." Games and Economic Behavior 6:347-369

Galeotti, Fabio, and Daniel J. Zizzo. 2014. "Competence versus Trustworthiness: What Do Voters Care About?” Working Paper. Available at: http://dx.doi.org/10.2139/ssrn.2408914.

Gambetta, Diego and Wojtek Przepiorka. 2014. "Natural and strategic generosity as signals of trustworthiness." PLOS ONE 9:e97533.

Gintis, Herbert, Eric A. Smith, and Samuel Bowles. 2001. "Costly Signaling and Cooperation." Journal of Theoretical Biology 213:103-119. 
Hamman, John R., Roberto A. Weber, and Jonathan Woon. 2011. An Experimental Investigation of Electoral Delegation and the Provision of Public Goods. American Journal of Political Science 55:738-752.

Harbaugh, William T., Ulrich Mayr, and Daniel R. Burghart. 2007. Neural responses to taxation and voluntary giving reveal motives for charitable donations. Science 316:1622-1625.

Holm, Hakan, and Peter Engseld. 2005. "Choosing Bargaining Partners - An Experimental Study on the Impact of Information About Income, Status and Gender." Experimental Economics $8: 183-216$.

Kartik, Navin, and R. Preston McAfee. 2007. Signaling character in electoral competition. American Economic Review 97:852-870.

Koppel, Hannes, and Tobias Regner. 2014. Corporate Social Responsibility in the work place. Experimental Economics 17:347-370.

Levi, Margaret, and Laura Stoker. 2000. Political trust and trustworthiness. Annual Review of Political Science 3:475-507.

McCabe, Kevin A., Mary L. Rigdon, and Vernon L. Smith. 2003. "Positive reciprocity and intentions in trust games." Journal of Economic Behavior \& Organization 52:267-275.

McEvily, Bill, Joseph R. Radzevick, and Roberto A. Weber. 2012. "Whom do you distrust and how much does it cost? An experiment on the measurement of trust." Games and Economic Behavior 74:285-298.

Milinski, Manfred, Dirk Semmann, and Hans-Jürgen Krambeck. (2002). Donors to charity gain in both indirect reciprocity and political reputation. Proceedings of the Royal Society $B$ 269:881-883.

Mondak, Jefferey J., and Robert Huckfeldt. 2006. The accessibility and utility of candidate character in electoral decision making. Electoral Studies 25:20-34.

Mood, Carina. 2010. "Logistic Regression: Why We Cannot Do What We Think We Can Do, and What We Can Do About It." European Sociological Review 26:67-82.

Noë, Ronald and Peter Hammerstein. 1994. "Biological markets: supply and demand determine the effect of partner choice in cooperation, mutualism and mating." Behavioral Ecology and Sociobiology 35:1-11.

Nyborg, Karine, and Tao Zhang. 2012. Is Corporate Social Responsibility Associated with Lower Wages? Environmental and Resource Economics 55:107-117.

Ong, David, and Chun-lei Yang. 2014. Pro Bono Work and Trust in Expert Fields. Mimeo. 
Page, Talbot, Louis Putterman, and Bulent Unel. 2005. "Voluntary Association in Public Goods Experiments: Reciprocity, Mimicry and Efficiency." Economic Journal 115:1032-1053.

Parker, Glenn R. 1989. The role of constituent trust in congressional elections. Public Opinion Quarterly 53:175-196.

Popkowski Leszczyc, Peter T. L., and Michael H. Rothkopf. 2010. Charitable Motives and Bidding in Charity Auctions. Management Science 56:399-413.

Przepiorka, Wojtek, and Andreas Diekmann. 2013. "Temporal Embeddedness and Signals of Trustworthiness: Experimental Tests of a Game Theoretic Model in the United Kingdom, Russia, and Switzerland.” European Sociological Review 29:1010-1023.

Przepiorka, Wojtek, and Ulf Liebe. 2016. "Generosity is a sign of trustworthiness - the punishment of selfishness is not." Evolution and Human Behavior: forthcoming.

Raub, Werner. 2004. "Hostage Posting as a Mechanism of Trust: Binding, Compensation, and Signaling." Rationality and Society 16:319-365.

Roberts, Gilbert. 1998. "Competitive altruism: from reciprocity to the handicap principle." Proceedings of the Royal Society B 265:427-431.

Slonim, Robert, and Ellen Garbarino. 2008. "Increases in trust and altruism from partner selection: Experimental evidence." Experimental Economics 11:134-153.

Sylwester, Karolina, and Gilbert Roberts. 2010. "Cooperators benefit through reputation-based partner choice in economic games." Biology Letters 6:659-662.

—. 2013. "Reputation-based partner choice is an effective alternative to indirect reciprocity in solving social dilemmas." Evolution and Human Behavior 34:201-206.

Tonin, Mirco, and Michael Vlassopoulos. 2015. Corporate Philanthropy and Productivity: Evidence from an Online Real Effort Experiment. Management Science 61: 1795-1811.

Toussaert, Séverine. 2014. Intention-Based Reciprocity and Signalling of Intentions. Mimeo.

Vlachos, Pavlos A., Argiris Tsamakos, Adam P. Vrechopoulos, and Panagiotis K. Avramidis. 2008. Corporate social responsibility: attributions, loyalty, and the mediating role of trust. Journal of the Academy of Marketing Science 37:170-180.

Yatchew, Adonis, and Zvi Griliches. 1985. "Specification Error in Probit Models." Review of Economics and Statistics 67:134-39. 


\section{Choosing a Partner for Social Exchange: Charitable Giving as a Signal of Trustworthiness}

Sebastian Fehrler ${ }^{\mathrm{a}, \mathrm{b}}$ and Wojtek Przepiorka ${ }^{\mathrm{c}, \mathrm{d}}$

${ }^{\text {a }}$ University of Konstanz, Department of Economics, Box 131, 78457 Konstanz, Germany

${ }^{\mathrm{b}}$ Institute for the Study of Labor (IZA), Schaumburg-Lippe-Str. 5-9, 53113 Bonn, Germany

c Utrecht University, Department of Sociology, Padualaan 14, $3584 \mathrm{CH}$ Utrecht, The Netherlands

${ }^{\mathrm{d}}$ Nuffield College, New Road, Oxford OX1 1NF, UK 


\section{Additional regression model estimations and figures}

Table A1: Transfers in the random matching part

\begin{tabular}{|c|c|c|c|c|c|c|}
\hline & \multicolumn{2}{|c|}{ (1) All transfers } & \multicolumn{2}{|c|}{$\begin{array}{l}\text { (2) Transfers if chosen } \\
\text { in partner choice part }\end{array}$} & \multicolumn{2}{|c|}{$\begin{array}{l}\text { (3) Transfers if not chosen } \\
\text { in partner choice part }\end{array}$} \\
\hline & DG & EG & DG & EG & DG & EG \\
\hline Donor & $1.36(0.21)$ & $6.66(0.57)$ & $2.23(0.31)$ & $6.85(0.59)$ & $0.35(0.17)$ & $5.86(1.59)$ \\
\hline Non-donor & $0.28(0.11)$ & $2.84(0.41)$ & $1.00(0.59)$ & $4.18(0.86)$ & $0.22(0.11)$ & $2.60(0.46)$ \\
\hline Uneq. Endow. & $1.04(0.19)$ & $4.12(0.50)$ & $1.80(0.34)$ & $4.41(0.79)$ & $0.52(0.19)$ & $4.00(0.63)$ \\
\hline Eq. endow. & $0.31(0.10)$ & $5.41(0.53)$ & $0.50(0.47)$ & $6.28(0.74)$ & $0.29(0.11)$ & $4.19(0.70)$ \\
\hline \multicolumn{7}{|c|}{$\begin{array}{l}\text { Notes: The table lists (1) in the random matching part the average transfers to the person Y types }\left(N_{1}=592, N_{2}=74\right) ;(2) \text { in } \\
\text { the random matching part the average transfers to the person Y types which the subject chose in the partner choice part }\left(N_{1}=\right. \\
\left.218, N_{2}=73\right) ;(3) \text { in the random matching part the average transfers to the person } \mathrm{Y} \text { types which the subject did not choose } \\
\text { in the partner choice part }\left(N_{1}=374, N_{2}=74\right) \text {. } N_{1} \text { denotes the number of decisions and } N_{2} \text { denotes the number of clusters (i.e. } \\
\text { subjects). Cluster robust standard errors are reported in parentheses. In the random matching part, the relative choice } \\
\text { frequencies are not available because person X subjects had to specify their transfer to each person Y type and did not have } \\
\text { the possibility to choose their interaction partner. In the partner choice part, transfers are average transfers after choice and } \\
\text { person X subjects could choose the category Indifferent if they were indifferent between two person Y types in a particular } \\
\text { choice set (see Figure 2). }\end{array}$} \\
\hline
\end{tabular}

Table A2: Logit models of person X exchange game partner choices

\begin{tabular}{|c|c|c|c|c|c|c|c|c|}
\hline & \multicolumn{2}{|c|}{ Logit 1} & \multicolumn{2}{|c|}{ Logit 2} & \multicolumn{2}{|c|}{ Logit 3} & \multicolumn{2}{|c|}{ Logit 4} \\
\hline & Coef & $\mathrm{SE}$ & Coef & SE & Coef & SE & Coef & SE \\
\hline \multicolumn{9}{|c|}{ Choice set $2($ chose donor $=1)$} \\
\hline Const. & $1.455^{* * *}$ & 0.299 & $1.292 * * *$ & 0.319 & $1.406 * * *$ & 0.352 & $1.216^{* *}$ & 0.382 \\
\hline$\Delta$ Beliefs & & & $1.518 * *$ & 0.527 & & & $1.524 * *$ & 0.518 \\
\hline$\Delta \mathrm{DG}$ trans. & & & & & 0.047 & 0.179 & 0.070 & 0.188 \\
\hline \multicolumn{9}{|c|}{ Choice set 4 (chose uneq. endow. $=1)$} \\
\hline Const. & $-0.860 * * *$ & 0.256 & -0.583 & 0.328 & $-1.217 * * *$ & 0.323 & $-0.948 *$ & 0.379 \\
\hline$\Delta$ Beliefs & & & 0.790 & 0.651 & & & 0.725 & 0.633 \\
\hline$\Delta \mathrm{DG}$ trans. & & & & & $0.432 *$ & 0.192 & $0.415^{*}$ & 0.188 \\
\hline$N_{1}$ & 148 & & 148 & & 148 & & 148 & \\
\hline$N_{2}$ & 74 & & 74 & & 74 & & 74 & \\
\hline pseudo $R^{2}$ & 0.20 & & 0.25 & & 0.23 & & 0.28 & \\
\hline$\chi_{(d f)}^{2}$ & $41.28(1)^{* * *}$ & & $35.64(3)^{* * *}$ & & $41.02(3)^{* * *}$ & & $36.88(5)^{* * * *}$ & \\
\hline
\end{tabular}


Table A3: (Marginal) probabilities of person X exchange game partner choices

\begin{tabular}{|c|c|c|c|c|c|c|c|c|}
\hline & \multicolumn{2}{|c|}{ Pr. 1} & \multicolumn{2}{|c|}{ Pr. 2} & \multicolumn{2}{|c|}{ Pr. 3} & \multicolumn{2}{|c|}{ Pr. 4} \\
\hline & Coef & SE & Coef & SE & Coef & SE & Coef & SE \\
\hline \multicolumn{9}{|c|}{ Choice set $2($ chose donor $=1)$} \\
\hline Const. & $0.811 * * *$ & 0.046 & $0.784 * * *$ & 0.054 & $0.803 * * *$ & 0.056 & $0.771 * * *$ & 0.067 \\
\hline$\Delta$ Beliefs & & & $0.207 * *$ & 0.066 & & & $0.215^{* *}$ & 0.067 \\
\hline$\Delta$ DG trans. & & & & & 0.007 & 0.028 & 0.012 & 0.032 \\
\hline \multicolumn{9}{|c|}{ Choice set 4 (chose uneq. endow. $=1)$} \\
\hline Const. & $0.297 * * *$ & 0.053 & $0.358 * * *$ & 0.075 & $0.228 * * *$ & 0.057 & $0.279 * * *$ & 0.076 \\
\hline$\Delta$ Beliefs & & & 0.161 & 0.128 & & & 0.127 & 0.109 \\
\hline$\Delta \mathrm{DG}$ trans. & & & & & $0.084^{*}$ & 0.033 & $0.088 *$ & 0.036 \\
\hline
\end{tabular}

Notes: The table lists marginal probabilities estimated from the logistic regression models presented in Table A1.

Table A4: Multinomial logit models of person X exchange game partner choices

\begin{tabular}{|c|c|c|c|c|c|c|c|c|}
\hline & \multicolumn{2}{|c|}{ MLogit 1} & \multicolumn{2}{|c|}{ MLogit 2} & \multicolumn{2}{|c|}{ MLogit 3} & \multicolumn{2}{|c|}{ MLogit 4} \\
\hline & Coef & SE & Coef & SE & Coef & SE & Coef & SE \\
\hline \multicolumn{9}{|c|}{$\begin{array}{l}\text { Choice set } 2 \\
1: \text { chose donor }\end{array}$} \\
\hline Const. & $1.696 * * *$ & 0.330 & $1.608 * * *$ & 0.373 & $1.648 * * *$ & 0.383 & $1.534 * *$ & 0.443 \\
\hline$\Delta$ Beliefs & & & $1.973 * *$ & 0.684 & & & $1.973 * *$ & 0.675 \\
\hline$\Delta \mathrm{DG}$ trans. & & & & & 0.047 & 0.188 & 0.067 & 0.201 \\
\hline \multicolumn{9}{|c|}{ 2: chose non-donor (base outcome) } \\
\hline \multicolumn{9}{|c|}{ 3: chose "indifferent" } \\
\hline Const. & $-1.299 *$ & 0.656 & -1.276 & 0.682 & -1.299 & 0.787 & -1.288 & 0.798 \\
\hline$\Delta$ Beliefs & & & $1.621^{*}$ & 0.769 & & & $1.611^{*}$ & 0.754 \\
\hline$\Delta$ DG trans. & & & & & $<0.0001$ & 0.435 & 0.011 & 0.427 \\
\hline \multicolumn{9}{|c|}{ Choice set 4} \\
\hline Const. & $-0.670 *$ & 0.264 & -0.442 & 0.338 & $-1.031 * *$ & 0.330 & $-0.816 *$ & 0.387 \\
\hline$\Delta$ Beliefs & & & 0.672 & 0.675 & & & 0.597 & 0.647 \\
\hline$\Delta \mathrm{DG}$ trans. & & & & & $0.440 *$ & 0.200 & $0.424 *$ & 0.197 \\
\hline \multicolumn{9}{|c|}{ 2: chose eq. endow. (base outcome) } \\
\hline \multicolumn{9}{|c|}{ 3: chose "indifferent" } \\
\hline Const. & $-1.564 * * *$ & 0.369 & $-1.893 * * *$ & 0.541 & $-1.586^{* * *}$ & 0.416 & $-1.928 * *$ & 0.612 \\
\hline$\Delta$ Beliefs & & & -0.703 & 0.763 & & & -0.724 & 0.775 \\
\hline$\Delta \mathrm{DG}$ trans. & & & & & 0.041 & 0.350 & 0.049 & 0.332 \\
\hline$N_{1}$ & 148 & & 148 & & 148 & & 148 & \\
\hline$N_{2}$ & 74 & & 74 & & 74 & & 74 & \\
\hline$\chi_{(d f)}^{2}$ & $69.76(4) * * *$ & & $63.52(8)^{* * *}$ & & $72.03(8)^{* * *}$ & & $67.33(12)^{* * *}$ & \\
\hline
\end{tabular}

Notes: The table lists coefficient estimates and cluster robust standard errors from multinomial logistic regression models $(* * * \mathrm{p}<0.001$, $* * \mathrm{p}<0.01, * \mathrm{p}<0.05$; for two-sided tests). The categorical dependent variable is one if the subject chose a donor or a person $\mathrm{Y}$ with an unequal endowment as their interaction partner in the exchange game, it is two if the subject chose a non-donor or an equally endowed person $\mathrm{Y}$, and it is three if the subject chose "indifferent." The variable $\Delta$ Beliefs is the difference in the average ratios of expected back transfers the subject had stated to have in choice sets 2 and 4 in the random matching part and ranges from -1.69 to 2.25 , with mean = 0.05 and median $=-0.14$. The variable $\Delta$ DG trans. is the difference in money transfers the subject made in choice set 1 or 3 in the random matching part and ranges from 0 to 6 , with mean $=0.91$ and median $=0 . N_{1}$ denotes the number of decisions and $N_{2}$ denotes the number of clusters. 
Table A5: (Marginal) probabilities of person X exchange game partner choices

\begin{tabular}{|c|c|c|c|c|c|c|c|c|}
\hline & \multicolumn{2}{|c|}{ Pr. 1} & \multicolumn{2}{|c|}{ Pr. 2} & \multicolumn{2}{|c|}{ Pr. 3} & \multicolumn{2}{|c|}{ Pr. 4} \\
\hline & Coef & SE & Coef & $\mathrm{SE}$ & Coef & SE & Coef & SE \\
\hline \multicolumn{9}{|c|}{$\begin{array}{l}\text { Choice set } 2 \\
\text { 1: chose donor }\end{array}$} \\
\hline Const. & $0.811 * * *$ & 0.046 & $0.796^{* * *}$ & 0.054 & $0.803 * * *$ & 0.056 & $0.784 * * *$ & 0.068 \\
\hline$\Delta$ Beliefs & & & $0.213 * *$ & 0.068 & & & $0.221 * *$ & 0.068 \\
\hline$\Delta \mathrm{DG}$ trans. & & & & & 0.007 & 0.028 & 0.010 & 0.031 \\
\hline \multicolumn{9}{|c|}{ 2: chose non-donor } \\
\hline Const. & $0.149 * * *$ & 0.042 & $0.159 * *$ & 0.049 & $0.155^{* *}$ & 0.050 & $0.169 * *$ & 0.062 \\
\hline$\Delta$ Beliefs & & & $-0.212 * *$ & 0.067 & & & $-0.220 * *$ & 0.068 \\
\hline$\Delta \mathrm{DG}$ trans. & & & & & -0.006 & 0.024 & -0.009 & 0.027 \\
\hline \multicolumn{9}{|c|}{ 3: chose "indifferent" } \\
\hline Const. & 0.041 & 0.023 & 0.045 & 0.026 & 0.042 & 0.029 & 0.047 & 0.032 \\
\hline$\Delta$ Beliefs & & & -0.002 & 0.016 & & & -0.002 & 0.016 \\
\hline$\Delta$ DG trans. & & & & & -0.002 & 0.016 & -0.002 & 0.017 \\
\hline \multicolumn{9}{|l|}{$\begin{array}{l}\text { Choice set } 4 \\
1 \text { : chose uneq }\end{array}$} \\
\hline Const. & $0.297 * * *$ & 0.053 & $0.358 * * *$ & 0.076 & $0.228 * * *$ & 0.057 & $0.279 * * *$ & 0.076 \\
\hline$\Delta$ Beliefs & & & 0.161 & 0.129 & & & 0.125 & 0.109 \\
\hline$\Delta$ DG trans. & & & & & $0.084 *$ & 0.033 & $0.089 *$ & 0.036 \\
\hline \multicolumn{9}{|c|}{ 2: chose eq. endow. } \\
\hline Const. & $0.581 * * *$ & 0.058 & $0.558 * * *$ & 0.077 & $0.640 * * *$ & 0.065 & $0.630 * * *$ & 0.083 \\
\hline$\Delta$ Beliefs & & & -0.065 & 0.134 & & & -0.028 & 0.123 \\
\hline$\Delta \mathrm{DG}$ trans. & & & & & -0.074 & 0.043 & $-0.081^{*}$ & 0.041 \\
\hline \multicolumn{9}{|c|}{ 3: chose "indifferent" } \\
\hline Const. & $0.122 * *$ & 0.038 & $0.084 *$ & 0.040 & $0.131 * *$ & 0.046 & 0.092 & 0.050 \\
\hline$\Delta$ Beliefs & & & -0.096 & 0.078 & & & -0.097 & 0.081 \\
\hline$\Delta$ DG trans. & & & & & -0.011 & 0.034 & -0.008 & 0.025 \\
\hline
\end{tabular}

Notes: The table lists marginal probabilities. 
Figure A1: Beliefs about person Y (tripled) back transfers in the EG by partner choice

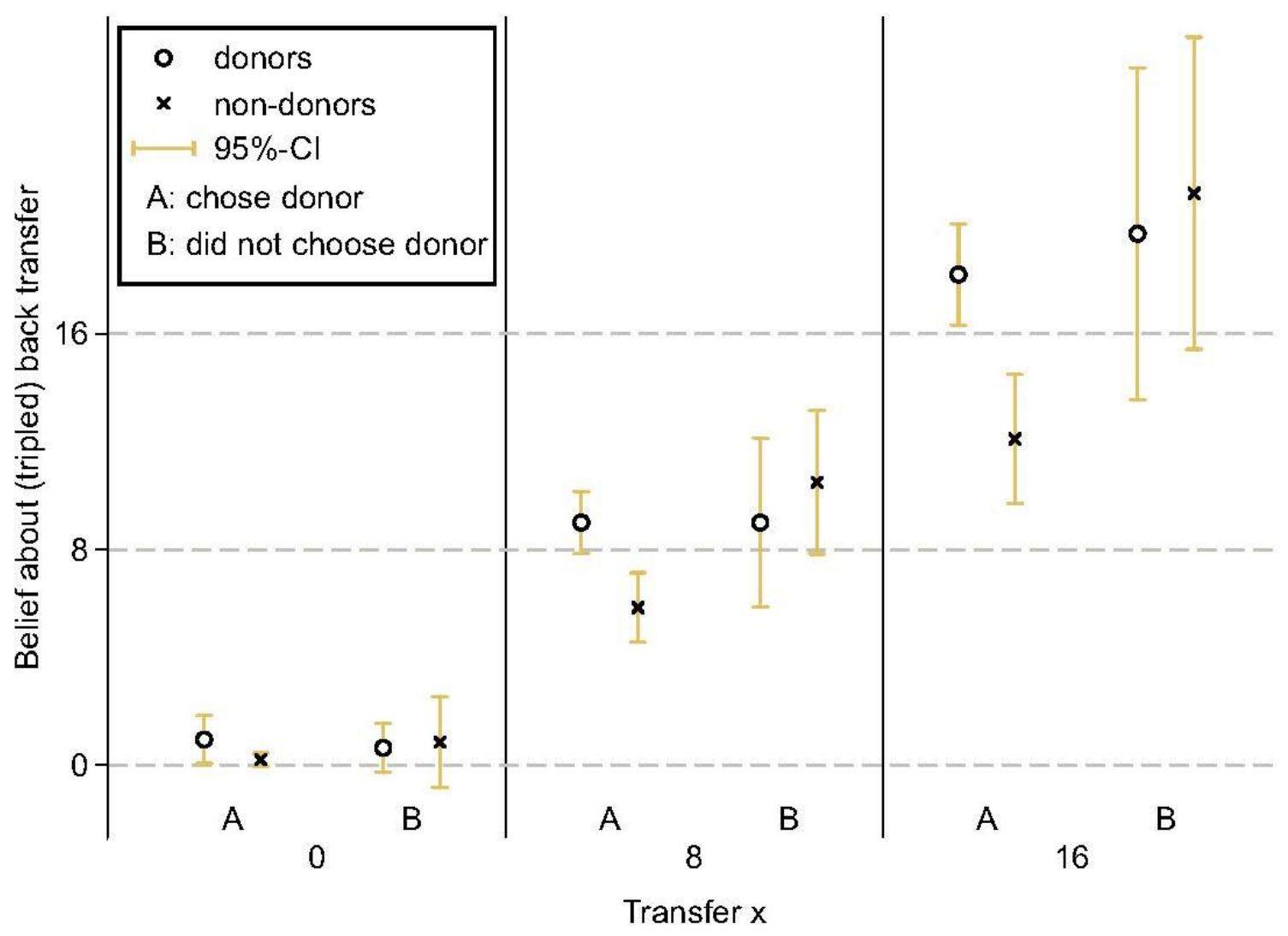




\section{Additional treatment}

Following the suggestion of a referee, we ran an additional treatment as a robustness check of our findings in the exchange game with partner choice between donors and non-donors. In this treatment we did not use the strategy method and let subjects interact for ten rounds. ${ }^{1}$ Subjects were assigned the role of trustee or trustor in round 1 for the whole session. In each round groups of one trustor and two trustees were randomly formed within matching groups of twelve subjects. In the beginning of each round the two trustees had the opportunity to donate EUR 6 out of their EUR 16 endowment to Amnesty International, Médecins Sans Frontières or the International Committee of the Red Cross, i.e., the same NGOs as in main treatment. ${ }^{2}$ Then, trustors learned whether either trustee had donated or not and had to choose one of them as their partner for the exchange game described in section 3.1. After round 10, one of the rounds was randomly selected and subjects paid out accordingly.

The share of trustees who donate is a little bit higher in the first two rounds but from round 3 onward it is very stable and ranges between 42.5 and $47.5 \%$ (Figure A2). There is very little variation in transfers (transfer $\mathrm{x}$ ) and back transfers (transfer y) over time. Regressing transfer $\mathrm{x}$ or transfer $\mathrm{y}$ on the round number gives no significant coefficient for "round number", e.g., there is no evidence for time trends.

In all choice situations in which the trustor had a choice between a trustee who donated and one who did not, donors are selected more often $(63.6 \%$ vs. $36.4 \%)$. Restricting attention to choices that were followed by a positive transfer $x$, i.e., ignoring situations in which nobody is trusted, donors are chosen $70.5 \%$ and non-donors $29.5 \%$ of the time. The difference is highly significant ( $\mathrm{p}=0.001$; $\mathrm{t}$-test with clustered standard errors at the matching group level). Donors who are selected as partners receive higher transfers than non-donors ( $\mathrm{p}=0.017$; t-test with clustered standard errors). ${ }^{3}$ Donors are neither more nor less trustworthy than non-donors. Regressing the back transfer on a dummy indicating whether a donation had been made, transfer $\mathrm{x}$, and transfer $\mathrm{x}$ interacted with the donation dummy (as in Table 5), results in a positive coefficient for the dummy and a negative coefficient for the interaction, the latter not being significantly different from zero $(\mathrm{p}=0.172)$ and the former only at the $10 \%$ level ( $\mathrm{p}=0.088$ ). Moreover, donating does not pay off monetarily, as in the main treatment.

\footnotetext{
${ }^{1}$ We report the experimental procedures and instructions at the end of the appendix.

${ }^{2}$ We ran this treatment in Konstanz, Germany. Hence, payments were in Euro rather than Swiss Francs (EUR $1 \approx$ CHF 1.1).

${ }^{3}$ Donors are chosen more often in every matching group (five) and receive higher transfers in all of them. These differences are thus also significant when we use non-parametric (binomial) tests.
} 
Figure A2: Behavior over time

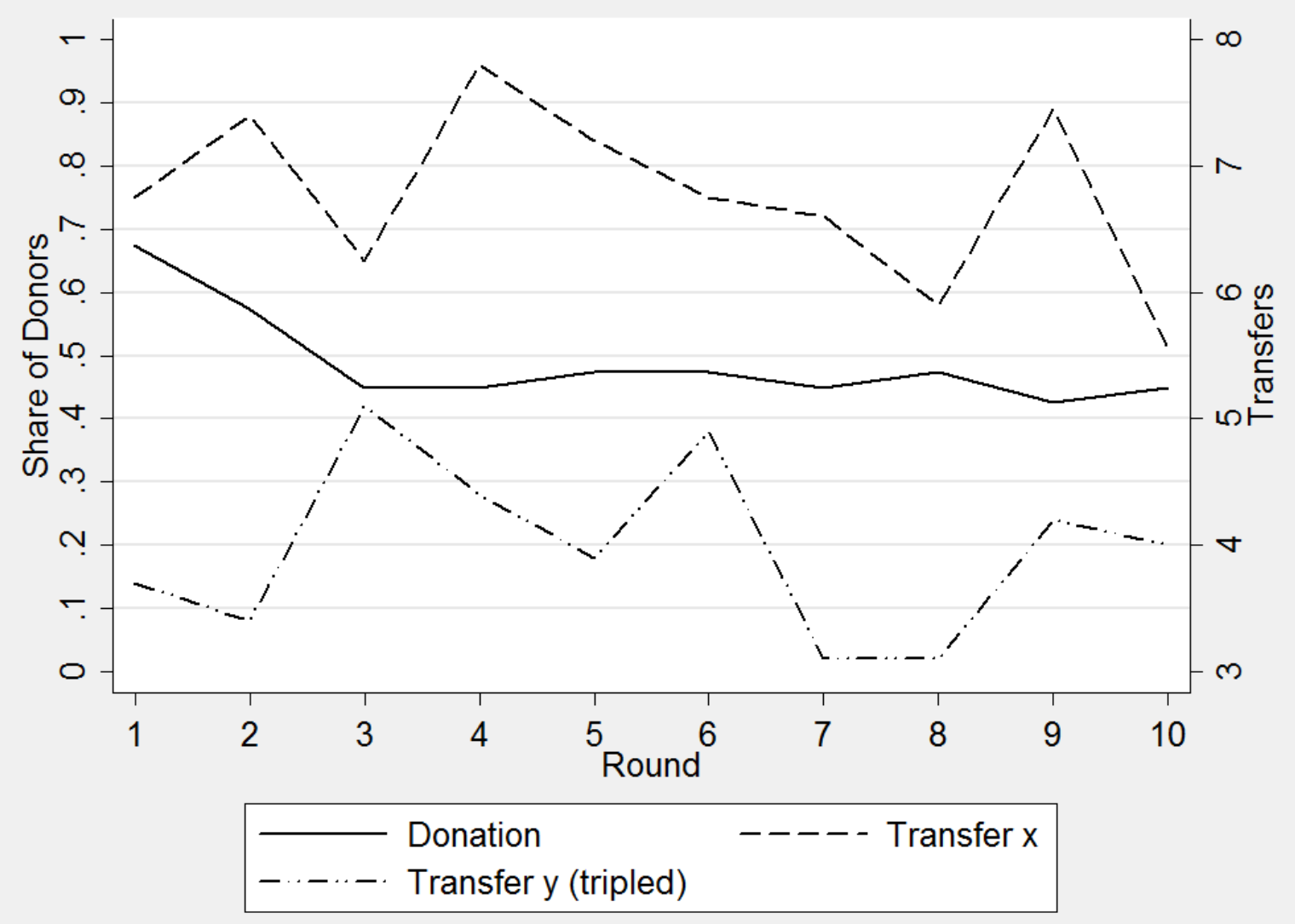

\section{Experimental procedures and instructions for main treatment}

\section{Experimental procedures}

Subjects ( $\mathrm{N}=148$ ) were students from the University of Zurich and ETH Zurich, $48 \%$ were female, and they were $23(\mathrm{sd}=4.42)$ years old on average. Upon arrival in the laboratory, subjects were randomly assigned to a cubicle and all subjects received the same set of instructions on paper. Instructions explained the decision situations step by step and contained shots of the actual decision screens, tables with all possible payoff combinations of the experimental games, and short descriptions of each charitable organization as well as instructions how to retrieve the donation receipts. Moreover, subjects learned that their decisions were anonymous, that their total earnings would be the sum of what they earned in the two parts of the experiment plus their show-up fee of CHF 10, and that their payments would be administered by a person not involved in the implementation of the experiment (see instructions in the online appendix for further details). After reading the instructions, subjects took a quiz with questions about the decision situations. Questions for which at least one wrong answer was given were read out loud and the correct answer was explained to all subjects at the same time. Then, subjects had the opportunity to ask questions. Questions were collected by the experimenters and, together with the correct answers, read out loud to all subjects. Only after all questions had been answered the experiment started. An experimental session lasted about 80 minutes 
(45 minutes intro, instructions and quiz; 35 minutes decisions and payments) and subjects earned CHF 39.85 ( $\approx$ US\$ 43.50) on average. After the experiment, subjects filled in a questionnaire, were paid in private at a counter and left the lab. The experiment was programmed and conducted with the software z-Tree (Fischbacher, 2007).

Instructions (translated from German by the authors; the German version is available on request)

\section{Experimental Instructions}

Please read these instructions attentively. It is important that you have understood the instructions before the experiment starts. You may take notes if you so wish.

You are participating in an experiment in which you will earn some money. The amounts you earn in the experiment will be added to your show-up fee of CHF 10. Your earnings depend on both the decisions you will make and the decisions other participants will make in the corresponding decision situations. There are no right or wrong decisions and you make all your decisions anonymously. At the end of the experiment, you will receive your earnings in private from an assistant that was not involved in the implementation of this experiment. All participants receive the same instructions and take part in the experiment under the same conditions. Please, from now on, do not talk to each other anymore and switch off your mobile devices. This experiment will last for about 80 minutes and it is being conducted by the Chair of Sociology at ETH Zurich. The data collected in this experiment are for scientific purposes only.

\section{Experiment}

There are two rounds. In each round, two persons (X and $\mathrm{Y}$ ) form a group (and the groups are newly formed in each round). You are either a person X or a person $\mathrm{Y}$. Whether you are person $\mathrm{X}$ or $\mathrm{Y}$ has been determined randomly by the seat you were given. You will be informed on the computer screen at the start of the experiment whether you are a person $\mathrm{X}$ or Y.

Persons Y are not all the same. Some persons Y receive an endowment of CHF 16 at the beginning of each round, and they have the possibility to donate CHF 6 of their endowment to a non-government organization listed in the Appendix (p 7). ${ }^{4}$ Other persons $\mathrm{Y}$ have no possibility to make a donation. Persons Y, who do not have a possibility to make a donation are not all the same either. Some receive an Endowment of CHF 16 while others receive an endowment of CHF 10. All persons Y thus have an endowment of CHF 16 or CHF 10 at the beginning of each round.

A person $\mathrm{X}$ decides how much of their endowment they want to transfer to a person $\mathrm{Y}$. There are two different transfer situations, A and B. In situation B, Person $\mathrm{Y}$ has the possibility to make a back transfer and the back transfer will be tripled. In situation A person $Y$ has no possibility to make a back transfer. This is the only difference between situation A and B. Table 1 on the next page presents the two transfer situations A and B schematically. Please study Table 1 attentively and then continue reading here.

The sequence of the two rounds is determined randomly. In one round, person $\mathrm{X}$ has the possibility to choose one of two persons $\mathrm{Y}$ to which they want to make a transfer, both in transfer situation $\mathrm{A}$ and $\mathrm{B}$.

\footnotetext{
${ }^{4}$ All donations made in the experiment will be summed up at the end and transferred to the non-government organizations (see the notes in the Appendix on $p$ 7).
} 
There are two different choice situations, 1 and 2. In choice situation 1, person $X$ can choose between persons $\mathrm{Y} 1$ and $\mathrm{Y} 2$. In choice situation 2, person $\mathrm{X}$ can choose between persons $\mathrm{Y} 3$ and $\mathrm{Y} 4$. The difference between persons $\mathrm{Y} 1$ and $\mathrm{Y} 2$ is that $\mathrm{Y} 1$ has made a donation and $\mathrm{Y} 2$ has not. The difference between persons $\mathrm{Y} 3$ and $\mathrm{Y} 4$ is that $\mathrm{Y} 3$ has an endowment of CHF 16 and Y4 has an endowment of CHF 10. If person $\mathrm{X}$ is indifferent between two persons $\mathrm{Y}$, they can leave their choice to chance. Figure 1 on page 3 presents the decision situation of person $X$ as it will appear on the computer screen in this round.

In another round, person $\mathrm{X}$ can again decide how much of their endowment of CHF 16 they want to transfer in both transfer situations A and B to persons Y1, Y2, Y3 and Y4. However, in this round, person $\mathrm{X}$ does not have the possibility to choose a person $\mathrm{Y}$ before deciding about a transfer. Figure 2 presents the decision situation of person $\mathrm{X}$ as it will appear on the computer screen in this round.

A person $\mathrm{Y}$ has to decide in both rounds in transfer situation B how much of their endowment they want to send back for every possible transfer a person X can make. Hereby, it has to be noted that the amount transferred to Person X will be tripled (see Table 1 situation B). Note that it can happen in the one round that a person $\mathrm{Y}$ is not chosen by the person $\mathrm{X}$ with which they were paired. In this case the decisions of person $\mathrm{Y}$ are not payoff relevant. Figure 3 on page 4 presents the decision situation of person $\mathrm{Y}$ as it will appear on the computer screen in both rounds.

Table 1: Transfer situations

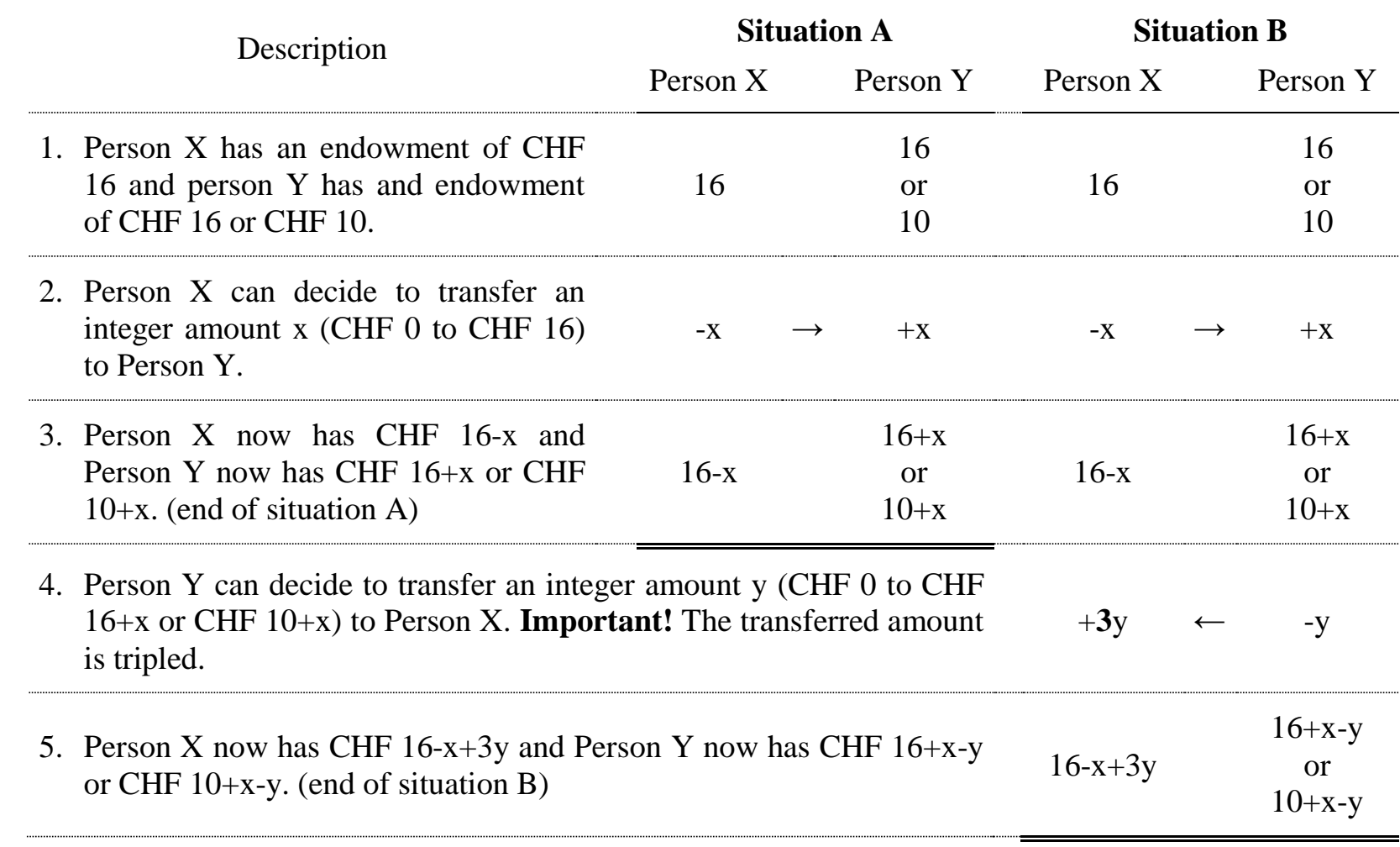

\section{Calculation of your earnings}

The transfer situations of person $\mathrm{X}$ are independent in both rounds. That is, each person $\mathrm{X}$ will be randomly assigned only one decision situation and thus only one person $\mathrm{Y}$ in each round. These assignments will be made only at the end. Depending on the type of person Y (Y1, Y2, Y3 or Y4), the transfer situation (A or B) and the decision made, the earnings of Person $\mathrm{X}$ and Person $\mathrm{Y}$ will be calculated according to Table 1. Persons $\mathrm{Y}$ who are not chosen in the one round, receive their 
endowment in this round. You will be paid the sum of your earnings in the two rounds and the showup fee of CHF 10 in cash at the end of the experiment.

Figure 1: Decision situation of person $\mathrm{X}$ in the round with the possibility to choose a person $\mathrm{Y}$

Situation 1-A: Both persons $Y$ have the same endowment as you (CHF 16 each). Both persons $Y$ had a possibility to make a donation. Person $Y 1$ made a donation of $\mathrm{CHF} 6$. Person $\mathrm{Y} 2$ did not make a donation. In this situation both persons $Y$ do not have a possibility to make a back transfer.

$$
\begin{aligned}
& \text { Your choice: } \\
& \sim \mathrm{Y} 1 \quad \sim \text { indifferent } \sim \mathrm{Y} 2
\end{aligned}
$$

Situation 1-B: Both persons $Y$ have the same endowment as you (CHF 16 each). Both persons $Y$ had a possibility to make a donation. Person $\mathrm{Y} 1$ made a donation of CHF 6 . Person $\mathrm{Y} 2$ did not make a donation. In this situation both persons $Y$ have a possibility to make a back transfer.

$\begin{array}{lll} & \text { Your choice: } & \text { Your transfer: } \\ \sim \text { Y1 } & \sim \text { indifferent } & \end{array}$

Situation 2-A: Person $Y 3$ has the same endowment as you (16 CHF) and Person $Y 4$ has an endowment of $\mathrm{CHF}$ 10. Both persons $Y$ did not have a possibility to make a donation. In this situation both persons $Y$ do not have a possibility to make a back transfer.
Your choice:
$\sim \mathrm{Y} 3 \quad \sim$ indifferent $\sim \mathrm{Y} 4$
Your transfer:

Situation 2-B: Person $Y 3$ has the same endowment as you (16 CHF) and Person $Y 4$ has an endowment of $\mathrm{CHF}$ 10. Both persons $Y$ did not have a possibility to make a donation. In this situation both persons $Y$ have a possibility to make a back transfer.

Your choice:

Your transfer:

$\sim \mathrm{Y} 3 \quad \sim$ indifferent $\sim \mathrm{Y} 4$

Figure 2: Decision situation of person $\mathrm{X}$ in the round without the possibility to choose a person $\mathrm{Y}$

Person $\mathrm{Y}$ has the same endowment as you (16 CHF), had a possibility to make a donation and does not have a possibility to make a back transfer.

Person $\mathrm{Y} 1$ made a donation of $\mathrm{CHF} 6$. How much do you transfer to $Y 1$ ?

|

Person $\mathrm{Y} 2$ did not make a donation. How much do you transfer to $Y 2$ ?

Person $\mathrm{Y}$ has the same endowment as you (16 CHF), had a possibility to make a donation and has a possibility to make a back transfer.

Person $\mathrm{Y} 1$ made a donation of $\mathrm{CHF} 6$. How much do you transfer to $Y 1$ ?

\section{Person Y2 did not make a donation.} How much do you transfer to $Y 2$ ?

Person $\mathrm{Y}$ did not have a possibility to make a donation and does not have a possibility to make a back transfer.

Person $\mathrm{Y} 3$ has the same endowment as you (CHF 16).

How much do you transfer to $Y 3$ ?
Person Y4 has an endowment of CHF 10.

How much do you transfer to $Y 4$ ?

Person $\mathrm{Y}$ did not have a possibility to make a donation and has a possibility to make a back transfer.

Person $Y 3$ has the same endowment as you (CHF 16).

How much do you transfer to $Y 3$ ?
Person $\mathrm{Y} 4$ has an endowment of $\mathrm{CHF} 10$.

How much do you transfer to $Y 4$ ? 
Figure 3: In both rounds person $\mathrm{Y}$ only decides in transfer situation $\mathrm{B}$

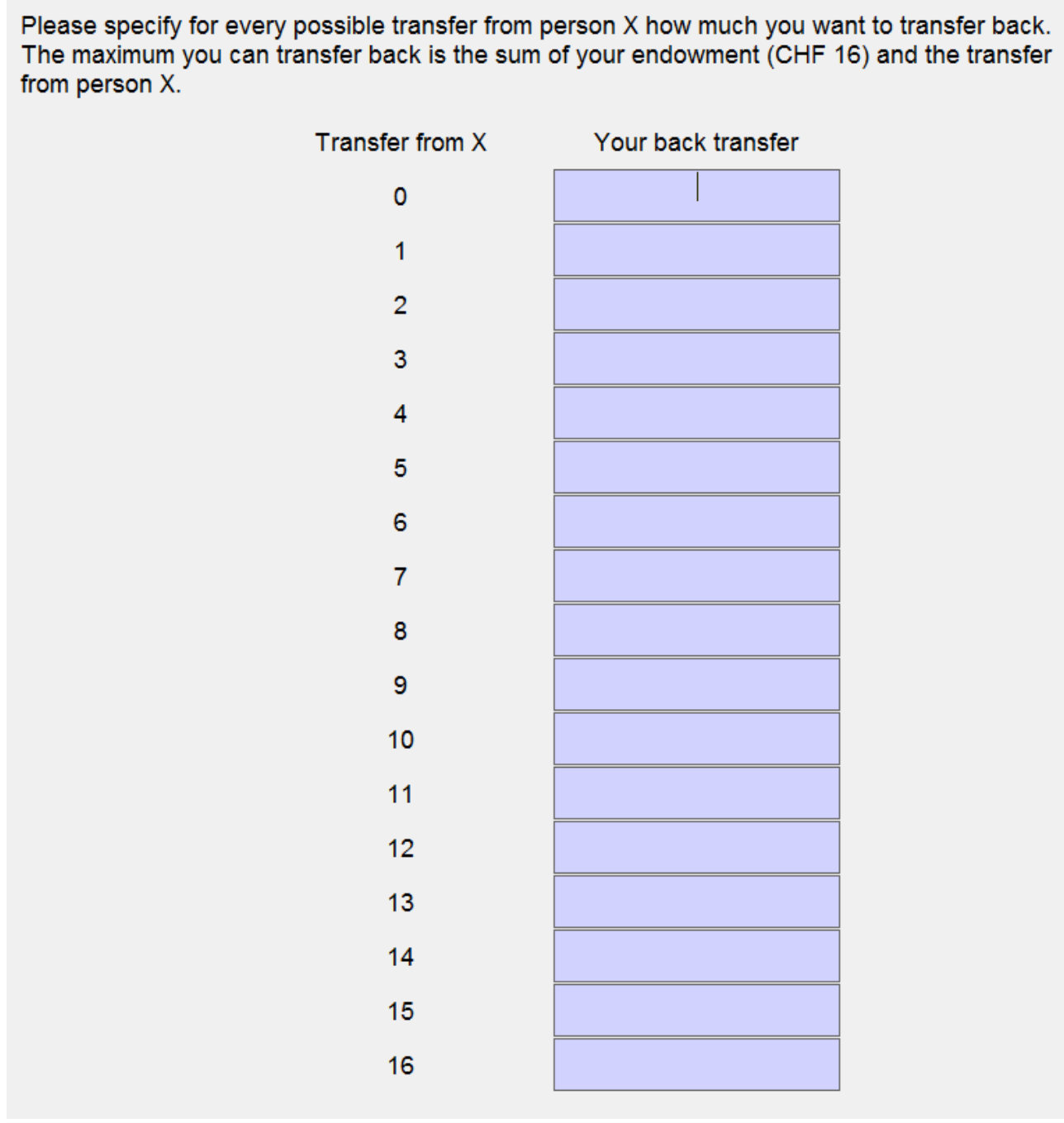

Tables 2 and 3 on the next two pages list the payoffs as a function of the transfer $\mathrm{x}$ made by person $\mathrm{X}$ and the back transfer y made by person Y. The first number in each cell corresponds to the payoff of person $\mathrm{X}$ and the second number in each cell corresponds to the payoff of person $\mathrm{Y}$. Table 2 lists the payoffs if both persons have an endowment of CHF 16 and Table 3 lists the payoffs if person $\mathrm{X}$ has an endowment of CHF 16 and person Y has an endowment of CHF 10. The first column in both tables $(\mathrm{y}=0)$ also lists the payoffs in transfer situation A. Please try to calculate the payoffs for some of the possible combinations of transfers $\mathrm{x}$ and $\mathrm{y}$ using both tables.

Next, five questions about the instructions will appear on your screen and you are asked to answer them. Your answers will help us to see whether you have understood everything correctly. Thereafter, we will continue with the experiment. 
Table 2: Payoff table I (both person X and Y have the same endowment of CHF 16)

2. Back transfer y out of $16+x$ (person $Y$ )

\begin{tabular}{|c|c|c|c|c|c|c|c|c|c|c|c|c|c|c|c|c|c|}
\hline & 0 & 1 & 2 & 3 & 4 & 5 & 6 & 7 & 8 & 9 & 10 & 11 & 12 & 13 & 14 & 15 & 16 \\
\hline 0 & $16 ; 16$ & $19 ; 15$ & $22 ; 14$ & $25 ; 13$ & $28 ; 12$ & $31 ; 11$ & $34 ; 10$ & $37 ; 9$ & $40 ; 8$ & $43 ; 7$ & $46 ; 6$ & $49 ; 5$ & $52 ; 4$ & $55 ; 3$ & $58 ; 2$ & $61 ; 1$ & $64 ; 0$ \\
\hline 1 & $15 ; 17$ & $18 ; 16$ & $21 ; 15$ & $24 ; 14$ & $27 ; 13$ & $30 ; 12$ & $33 ; 11$ & $36 ; 10$ & $39 ; 9$ & $42 ; 8$ & $45 ; 7$ & $48 ; 6$ & $51 ; 5$ & $54 ; 4$ & $57 ; 3$ & $60 ; 2$ & $63 ; 1$ \\
\hline 2 & $14 ; 18$ & $17 ; 17$ & $20 ; 16$ & $23 ; 15$ & $26 ; 14$ & $29 ; 13$ & $32 ; 12$ & $35 ; 11$ & $38 ; 10$ & $41 ; 9$ & $44 ; 8$ & $47 ; 7$ & $50 ; 6$ & $53 ; 5$ & $56 ; 4$ & $59 ; 3$ & $62 ; 2$ \\
\hline 3 & $13 ; 19$ & $16 ; 18$ & $19 ; 17$ & $22 ; 16$ & $25 ; 15$ & $28 ; 14$ & $31 ; 13$ & $34 ; 12$ & $37 ; 11$ & $40 ; 10$ & $43 ; 9$ & $46 ; 8$ & $49 ; 7$ & $52 ; 6$ & $55 ; 5$ & $58 ; 4$ & $61 ; 3$ \\
\hline 4 & $12 ; 20$ & $15 ; 19$ & $18 ; 18$ & $21 ; 17$ & $24 ; 16$ & $27 ; 15$ & $30 ; 14$ & $33 ; 13$ & $36 ; 12$ & $39 ; 11$ & $42 ; 10$ & $45 ; 9$ & $48 ; 8$ & $51 ; 7$ & $54 ; 6$ & $57 ; 5$ & $60 ; 4$ \\
\hline 5 & $11 ; 21$ & $14 ; 20$ & $17 ; 19$ & $20 ; 18$ & $23 ; 17$ & $26 ; 16$ & $29 ; 15$ & $32 ; 14$ & $35 ; 13$ & $38 ; 12$ & $41 ; 11$ & $44 ; 10$ & $47 ; 9$ & $50 ; 8$ & $53 ; 7$ & $56 ; 6$ & $59 ; 5$ \\
\hline 6 & $10 ; 22$ & $13 ; 21$ & $16 ; 20$ & $19 ; 19$ & $22 ; 18$ & $25 ; 17$ & $28 ; 16$ & $32 ; 15$ & $34 ; 14$ & $37 ; 13$ & $40 ; 12$ & $43 ; 11$ & $46 ; 10$ & $49 ; 9$ & $52 ; 8$ & $55 ; 7$ & $58 ; 6$ \\
\hline 7 & $9 ; 23$ & $12 ; 22$ & $15 ; 21$ & $18 ; 20$ & $21 ; 19$ & $24 ; 18$ & $27 ; 17$ & $30 ; 16$ & $33 ; 15$ & $36 ; 14$ & $39 ; 13$ & $42 ; 12$ & $45 ; 11$ & $48 ; 10$ & $51 ; 9$ & $54 ; 8$ & $57 ; 7$ \\
\hline 8 & $8 ; 24$ & $11 ; 23$ & $14 ; 22$ & $17 ; 21$ & $20 ; 20$ & $23 ; 19$ & $26 ; 18$ & $29 ; 17$ & $32 ; 16$ & $35 ; 15$ & $38 ; 14$ & $41 ; 13$ & $44 ; 12$ & $47 ; 11$ & $50 ; 10$ & $53 ; 9$ & $56 ; 8$ \\
\hline 9 & $7 ; 25$ & $10 ; 24$ & $13 ; 23$ & $16 ; 22$ & $19 ; 21$ & $22 ; 20$ & $25 ; 19$ & $28 ; 18$ & $31 ; 17$ & $34 ; 16$ & $37 ; 15$ & $40 ; 14$ & $43 ; 13$ & $46 ; 12$ & $49 ; 11$ & $52 ; 10$ & $55 ; 9$ \\
\hline 10 & $6 ; 26$ & $9 ; 25$ & $12 ; 24$ & $15 ; 23$ & $18 ; 22$ & $21 ; 21$ & $24 ; 20$ & $27 ; 19$ & $30 ; 18$ & $33 ; 17$ & $36 ; 16$ & $39 ; 15$ & $42 ; 14$ & $45 ; 13$ & $48 ; 12$ & $51 ; 11$ & $54 ; 10$ \\
\hline 11 & $5 ; 27$ & $8 ; 26$ & $11 ; 25$ & $14 ; 24$ & $17 ; 23$ & $20 ; 22$ & $23 ; 21$ & $26 ; 20$ & $29 ; 19$ & $32 ; 18$ & $35 ; 17$ & $38 ; 16$ & $41 ; 15$ & $44 ; 14$ & $47 ; 13$ & $50 ; 12$ & $53 ; 11$ \\
\hline 12 & $4 ; 28$ & $7 ; 27$ & $10 ; 26$ & $13 ; 25$ & $16 ; 24$ & $19 ; 23$ & $22 ; 22$ & $25 ; 21$ & $28 ; 20$ & $31 ; 19$ & $34 ; 18$ & $37 ; 17$ & $40 ; 16$ & $43 ; 15$ & $46 ; 14$ & $49 ; 13$ & $52 ; 12$ \\
\hline 13 & $3 ; 29$ & $6 ; 28$ & $9 ; 27$ & $12 ; 26$ & $15 ; 25$ & $18 ; 24$ & $21 ; 23$ & $24 ; 22$ & $27 ; 21$ & $30 ; 20$ & $33 ; 19$ & $36 ; 18$ & $39 ; 17$ & $42 ; 16$ & $45 ; 15$ & $48 ; 14$ & $51 ; 13$ \\
\hline 14 & $2 ; 30$ & $5 ; 29$ & $8 ; 28$ & $11 ; 27$ & $14 ; 26$ & $17 ; 25$ & $20 ; 24$ & $23 ; 23$ & $26 ; 22$ & $29 ; 21$ & $32 ; 20$ & $35 ; 19$ & $38 ; 18$ & $41 ; 17$ & $44 ; 16$ & $47 ; 15$ & $50 ; 14$ \\
\hline 15 & $1 ; 31$ & $4 ; 30$ & $7 ; 29$ & $10 ; 28$ & $13 ; 27$ & $16 ; 26$ & $19 ; 25$ & $22 ; 24$ & $25 ; 23$ & $28 ; 22$ & $31 ; 21$ & $34 ; 20$ & $37 ; 19$ & $40 ; 18$ & $43 ; 17$ & $46 ; 16$ & $49 ; 15$ \\
\hline 16 & $0 ; 32$ & $3 ; 31$ & $6 ; 30$ & $9 ; 29$ & $12 ; 28$ & $15 ; 27$ & $18 ; 26$ & $21 ; 25$ & $24 ; 24$ & $27 ; 23$ & $30 ; 22$ & $33 ; 21$ & $36 ; 20$ & $39 ; 19$ & $42 ; 18$ & $48 ; 17$ & $48 ; 16$ \\
\hline
\end{tabular}

Table 2: ... continued

2. Back transfer y out of $16+x$ (person $Y$ )

\begin{tabular}{|c|c|c|c|c|c|c|c|c|c|c|c|c|c|c|c|c|}
\hline & 17 & 18 & 19 & 20 & 21 & 22 & 23 & 24 & 25 & 26 & 27 & 28 & 29 & 30 & 31 & 32 \\
\hline 0 & - & - & - & - & - & - & - & - & - & - & - & - & - & - & - & - \\
\hline 1 & $66 ; 0$ & - & - & - & - & - & - & - & - & - & - & - & - & - & - & - \\
\hline 2 & $65 ; 1$ & $68 ; 0$ & - & - & - & - & - & - & - & - & - & - & - & - & - & - \\
\hline 3 & $64 ; 2$ & $67 ; 1$ & $70 ; 0$ & - & - & - & - & - & - & - & - & - & - & - & - & - \\
\hline 4 & $63 ; 3$ & $66 ; 2$ & $69 ; 1$ & $72 ; 0$ & - & - & - & - & - & - & - & - & - & - & - & - \\
\hline 5 & $62 ; 4$ & $65 ; 3$ & $68 ; 2$ & $71 ; 1$ & $74 ; 0$ & - & - & - & - & - & - & - & - & - & - & - \\
\hline 6 & $61 ; 5$ & $64 ; 4$ & $67 ; 3$ & $70 ; 2$ & $73 ; 1$ & $76 ; 0$ & - & - & - & - & - & - & - & - & - & - \\
\hline 7 & $60 ; 6$ & $63 ; 5$ & $66 ; 4$ & $69 ; 3$ & $72 ; 2$ & $75 ; 1$ & $78 ; 0$ & - & - & - & - & - & - & - & - & - \\
\hline 8 & $59 ; 7$ & $62 ; 6$ & $65 ; 5$ & $68 ; 4$ & $71 ; 3$ & $74 ; 2$ & $77 ; 1$ & $80 ; 0$ & - & - & - & - & - & - & - & - \\
\hline 9 & $58 ; 8$ & $61 ; 7$ & $64 ; 6$ & $67 ; 5$ & $70 ; 4$ & $73 ; 3$ & $76 ; 2$ & $79 ; 1$ & $82 ; 0$ & - & - & - & - & - & - & - \\
\hline 10 & $57 ; 9$ & $60 ; 8$ & $63 ; 7$ & $66 ; 6$ & $69 ; 5$ & $72 ; 4$ & $75 ; 3$ & $78 ; 2$ & $81 ; 1$ & $84 ; 0$ & - & - & - & - & - & - \\
\hline 11 & $56 ; 10$ & $59 ; 9$ & $62 ; 8$ & $65 ; 7$ & $68 ; 6$ & $71 ; 5$ & $74 ; 4$ & $77 ; 3$ & $80 ; 2$ & $83 ; 1$ & $86 ; 0$ & - & - & - & - & - \\
\hline 12 & $55 ; 11$ & $58 ; 10$ & $61 ; 9$ & $64 ; 8$ & $67 ; 7$ & $70 ; 6$ & $73 ; 5$ & $76 ; 4$ & $79 ; 3$ & $82 ; 2$ & $85 ; 1$ & $88 ; 0$ & - & - & - & - \\
\hline 13 & $54 ; 12$ & $57 ; 11$ & $60 ; 10$ & $63 ; 9$ & $66 ; 8$ & $69 ; 7$ & $72 ; 6$ & $75 ; 5$ & $78 ; 4$ & $81 ; 3$ & $84 ; 2$ & $87 ; 1$ & $90 ; 0$ & - & - & - \\
\hline 14 & $53 ; 13$ & $56 ; 12$ & $59 ; 11$ & $62 ; 10$ & $65 ; 9$ & $68 ; 8$ & $71 ; 7$ & $74 ; 6$ & $77 ; 5$ & $80 ; 4$ & $83 ; 3$ & $86 ; 2$ & $89 ; 1$ & $92 ; 0$ & - & - \\
\hline 15 & $52 ; 14$ & $55 ; 13$ & $58 ; 12$ & $61 ; 11$ & $64 ; 10$ & $67 ; 9$ & $70 ; 8$ & $73 ; 7$ & $76 ; 6$ & $79 ; 5$ & $82 ; 4$ & $85 ; 3$ & $88 ; 2$ & $91 ; 1$ & $94 ; 0$ & - \\
\hline 16 & $51 ; 15$ & $54 ; 14$ & $57 ; 13$ & $60 ; 12$ & $63 ; 11$ & $66 ; 10$ & $69 ; 9$ & $72 ; 8$ & $75 ; 7$ & $78 ; 6$ & $81 ; 5$ & $84 ; 4$ & $87 ; 3$ & $90 ; 2$ & $93 ; 1$ & $96 ; 0$ \\
\hline
\end{tabular}

Payoff person $X: 16-x+3 y$

Payoff person Y: $16+x-y$

(Situation A corresponds to the first column in the table; $y=0$ ) 
Table 3: Payoff table III (person X has an endowment of CHF 16 and person Y has an endowment of CHF 10)

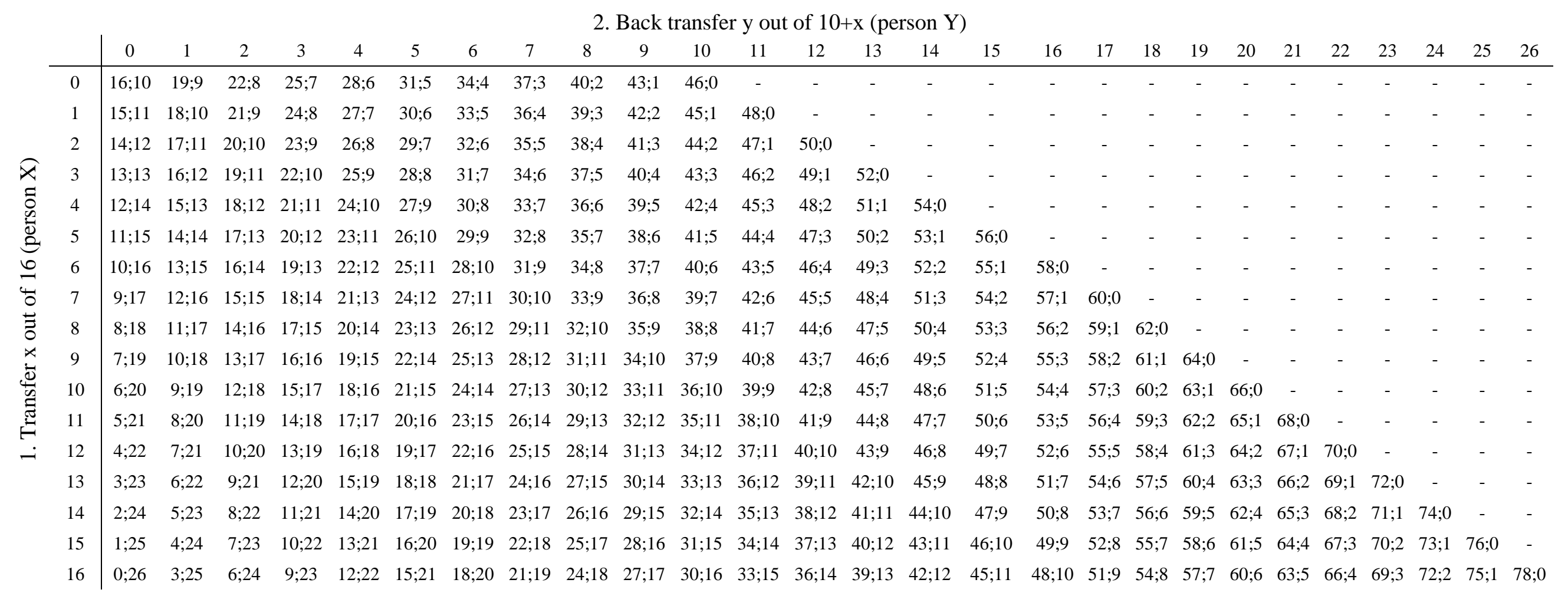

Payoff person X: $16-x+3 y$

Payoff person $Y$ : $10+x-y$

(Situation A corresponds to the first column in the table; $y=0$ ) 


\section{Appendix}

Persons $\mathrm{Y}$ who have a possibility to make a donation can decide at the beginning of each round whether or not they want to make a donation. In each round, donations can be made by each person only to one of the following non-government organizations:

\section{Amnesty International (AI)}

AI is a global movement which campaigns for the adherence and promotion of human rights as enshrined in the Universal Declaration of Human Rights.

International Committee of the Red Cross (ICRC)

The ICRC campaigns for the protection of the life and the dignity of all victims of wars and national violence and for the support of the affected people as well as the prevention of human suffering through the promotion and strengthening of the law and universal human rights.

Médecins Sans Frontières (MSF)

MSF helps people in need, victims of natural or human made disasters as well as armed conflicts, without discrimination and irrespective of their ethnic origins, religious, philosophical or political beliefs.

\section{Note}

After the conclusion of this experiment (April 2011) all donations made will be summed up and transferred to the corresponding non-government organizations. You can inspect the pay-in slips upon request at the Chair of Sociology (ETH). Please contact Ms Noemi Blättler (noemib@ethz.ch).

\section{Experimental procedures and instructions for the additional treatment}

\section{Experimental Procedures}

As neither of the authors had access to the lab in Zurich anymore, we ran the additional treatment in the Lakelab at the University of Konstanz. The 60 subjects, 55\% of them female, were on average 21.1 years old $(\mathrm{sd}=2.4)$. Upon arrival in the laboratory, subjects were randomly assigned to a cubicle and all subjects received the same set of instructions on paper (see online appendix for the complete instructions). After reading the instructions, subjects took a quiz with questions about the decision situations. Questions for which at least one wrong answer was given were read out loud and the correct answer was explained to all subjects at the same time. Then, subjects had the opportunity to ask questions. Questions were collected by the experimenters and, together with the correct answers, read out loud to all subjects. Only after all questions had been answered the experiment started. An experimental session lasted about 85 minutes (35 minutes intro, instructions and quiz; 50 minutes 
decisions and payments) and subjects earned EUR $18(\approx$ US\$ 19.6), on average, which corresponds to the lab rules regarding average expected earnings and includes a show-up fee of EUR 2. After the experiment, subjects filled in a questionnaire, were paid in private and left the lab.

Instructions (translated from German by the authors; the German version is available on request)

\section{Experimental Instructions}

\section{Overview}

It is important that you understand these instructions before the experiment begins.

You are participating in an experiment in which you can earn money. How much you earn will depend on your decisions and the decisions of other participants in the decision situations. There are no right or wrong decisions and all decisions are made anonymously. You will be paid out in private at the end by an assistant that was not involved in the implementation of this experiment. All participants receive the same set of instructions and participate under the same conditions. Please, stop talking to each other at this point and switch off your mobile phones.

In this experiment, all interactions between the participants are via the computers you are sitting in front of. You will interact anonymously with each other. Neither your name nor the names of other participants will be made public. Only the anonymized data will be used for the data analysis.

Today's session has several rounds. One round will be randomly selected in the end and paid out. The other rounds are not paid out. Your earnings result from your pay-off in the selected round plus 2 euro for answering the questionnaire at the end.

All participants are paid out in private so that other participants cannot see how much you have earned.

\section{Groups and Roles}

In the very beginning, participants are grouped into meta-groups of 12 participants.

Then 10 rounds are played. In the beginning of each round, new groups of 3 are randomly formed within the meta-group. This means that in every round you will be in a group with different participants with a high probability.

In this experiment, you are either a Person X or a Person Y. Whether you are a Person X or a Person $Y$, will be determined in the first round for the whole experiment. You will learn your role on the first screen. One third of the participants will be assigned the role Person X, two thirds will be assigned the 
role Person Y. At the beginning of each round the groups of three are built such that they consist of one Person $\mathrm{X}$ and two Persons Y.

\section{Round structure}

All 10 rounds have the identical structure.

At the beginning of a round all three group members receive EUR 16. Now, Persons Y can independently decide whether they want to donate EUR 6 to a Non-Governmental Organization (NGO). The NGOs that can be chosen are briefly portrayed at the end of the instructions.

The Person $\mathrm{X}$ in the group then learns about the decisions whether or not to donate of both Persons $\mathrm{Y}$ in her group. She does not learn, however, which NGO was chosen in case of a donation. Now, Person $\mathrm{X}$ selects one of the Persons Y from her group and decides how much of her endowment of EUR 16 she wants to transfer to this Person Y (amount $\mathrm{x}$ ). The selected Person $\mathrm{Y}$ then learns how much Person $\mathrm{X}$ has transferred and can make a back transfer (amount $\mathrm{y}$ ) that is tripled. At the end of a round subjects receive a brief feedback regarding the decisions of the other group members and their payoff that is realized in case this round gets randomly selected in the end.

\section{Payoff Computation}

In every round the payoffs are computed as follows:

Person X: EUR 16 EUR endowment - transfer to Person Y + 3 times back transfer from Person $Y$

Person Y (selected by X): EUR 16 endowment (- EUR 6 in case a donation has been made) + transfer from Person $\mathrm{X}$ - back transfer to Person $\mathrm{X}$

Person Y (not selected): EUR 16 endowment (- EUR 6 in case a donation has been made)

Tables 1 and 2 at the end of the instructions list the round payoffs for all combinations of transfers from Person X (amount $\mathrm{x}$ ) and back transfers from Person Y (amount $\mathrm{y}$ ). The first number in each cell is the payoff to Person $\mathrm{X}$ and the second number the payoff to Person Y. Table 1 lists the payoffs for the case that the selected Person Y did not donate and Table 2 lists the payoffs for the case that the selected Person Y did donate.

At the end of the experiment one round will be randomly selected and the payoffs from that round will be paid out. In addition you will receive EUR 2 for answering the subsequent questionnaire.

\section{Donations}

As described above, Persons Y can decide at the beginning of each round, whether or not they want to make a donation. Donations can be only be made to one of the following NGOs: 


\section{Amnesty International (AI)}

$\mathrm{AI}$ is a global movement which campaigns for the adherence and promotion of human rights as enshrined in the Universal Declaration of Human Rights.

\section{International Committee of the Red Cross (ICRC)}

The ICRC campaigns for the protection of the life and the dignity of all victims of wars and national violence and for the support of the affected people as well as the prevention of human suffering through the promotion and strengthening of the law and universal human rights.

\section{Médecins Sans Frontières (MSF)}

MSF helps people in need, victims of natural or human made disasters as well as armed conflicts, without discrimination and irrespective of their ethnic origins, religious, philosophical or political beliefs.

Note

After the conclusion of this experiment (Februar 2016) all donations made will be summed up and transferred to the corresponding non-government organizations. You can inspect the pay-in slips upon request at the Chair of Behavioral Economics. Please contact Sebastian Fehrler (sebastian.fehrler@uni-konstanz.de). 
Table 1: Payoff table for the case that Person Y did not donate (Payoff X; Payoff Y)

2. Back transfer y out of $16+x$ (person $Y$ )

\begin{tabular}{|c|c|c|c|c|c|c|c|c|c|c|c|c|c|c|c|c|c|}
\hline & 0 & 1 & 2 & 3 & 4 & 5 & 6 & 7 & 8 & 9 & 10 & 11 & 12 & 13 & 14 & 15 & 16 \\
\hline 0 & $16 ; 16$ & $19 ; 15$ & $22 ; 14$ & $25 ; 13$ & $28 ; 12$ & $31 ; 11$ & $34 ; 10$ & $37 ; 9$ & $40 ; 8$ & $43 ; 7$ & $46 ; 6$ & $49 ; 5$ & $52 ; 4$ & $55 ; 3$ & $58 ; 2$ & $61 ; 1$ & $64 ; 0$ \\
\hline 1 & $15 ; 17$ & $18 ; 16$ & $21 ; 15$ & $24 ; 14$ & $27 ; 13$ & $30 ; 12$ & $33 ; 11$ & $36 ; 10$ & $39 ; 9$ & $42 ; 8$ & $45 ; 7$ & $48 ; 6$ & $51 ; 5$ & $54 ; 4$ & $57 ; 3$ & $60 ; 2$ & $63 ; 1$ \\
\hline 2 & $14 ; 18$ & $17 ; 17$ & $20 ; 16$ & $23 ; 15$ & $26 ; 14$ & $29 ; 13$ & $32 ; 12$ & $35 ; 11$ & $38 ; 10$ & $41 ; 9$ & $44 ; 8$ & $47 ; 7$ & $50 ; 6$ & $53 ; 5$ & $56 ; 4$ & $59 ; 3$ & $62 ; 2$ \\
\hline 3 & $13 ; 19$ & $16 ; 18$ & $19 ; 17$ & $22 ; 16$ & $25 ; 15$ & $28 ; 14$ & $31 ; 13$ & $34 ; 12$ & $37 ; 11$ & $40 ; 10$ & $43 ; 9$ & $46 ; 8$ & $49 ; 7$ & $52 ; 6$ & $55 ; 5$ & $58 ; 4$ & $61 ; 3$ \\
\hline 4 & $12 ; 20$ & $15 ; 19$ & $18 ; 18$ & $21 ; 17$ & $24 ; 16$ & $27 ; 15$ & $30 ; 14$ & $33 ; 13$ & $36 ; 12$ & $39 ; 11$ & $42 ; 10$ & $45 ; 9$ & $48 ; 8$ & $51 ; 7$ & $54 ; 6$ & $57 ; 5$ & $60 ; 4$ \\
\hline 5 & $11 ; 21$ & $14 ; 20$ & $17 ; 19$ & $20 ; 18$ & $23 ; 17$ & $26 ; 16$ & $29 ; 15$ & $32 ; 14$ & $35 ; 13$ & $38 ; 12$ & $41 ; 11$ & $44 ; 10$ & $47 ; 9$ & $50 ; 8$ & $53 ; 7$ & $56 ; 6$ & $59 ; 5$ \\
\hline 6 & $10 ; 22$ & $13 ; 21$ & $16 ; 20$ & $19 ; 19$ & $22 ; 18$ & $25 ; 17$ & $28 ; 16$ & $32 ; 15$ & $34 ; 14$ & $37 ; 13$ & $40 ; 12$ & $43 ; 11$ & $46 ; 10$ & $49 ; 9$ & $52 ; 8$ & $55 ; 7$ & $58 ; 6$ \\
\hline 7 & $9 ; 23$ & $12 ; 22$ & $15 ; 21$ & $18 ; 20$ & $21 ; 19$ & $24 ; 18$ & $27 ; 17$ & $30 ; 16$ & $33 ; 15$ & $36 ; 14$ & $39 ; 13$ & $42 ; 12$ & $45 ; 11$ & $48 ; 10$ & $51 ; 9$ & $54 ; 8$ & $57 ; 7$ \\
\hline 8 & $8 ; 24$ & $11 ; 23$ & $14 ; 22$ & $17 ; 21$ & $20 ; 20$ & $23 ; 19$ & $26 ; 18$ & $29 ; 17$ & $32 ; 16$ & $35 ; 15$ & $38 ; 14$ & $41 ; 13$ & $44 ; 12$ & $47 ; 11$ & $50 ; 10$ & $53 ; 9$ & $56 ; 8$ \\
\hline 9 & $7 ; 25$ & $10 ; 24$ & $13 ; 23$ & $16 ; 22$ & $19 ; 21$ & $22 ; 20$ & $25 ; 19$ & $28 ; 18$ & $31 ; 17$ & $34 ; 16$ & $37 ; 15$ & $40 ; 14$ & $43 ; 13$ & $46 ; 12$ & $49 ; 11$ & $52 ; 10$ & $55 ; 9$ \\
\hline 10 & $6 ; 26$ & $9 ; 25$ & $12 ; 24$ & $15 ; 23$ & $18 ; 22$ & $21 ; 21$ & $24 ; 20$ & $27 ; 19$ & $30 ; 18$ & $33 ; 17$ & $36 ; 16$ & $39 ; 15$ & $42 ; 14$ & $45 ; 13$ & $48 ; 12$ & $51 ; 11$ & $54 ; 10$ \\
\hline 11 & $5 ; 27$ & $8 ; 26$ & $11 ; 25$ & $14 ; 24$ & $17 ; 23$ & $20 ; 22$ & $23 ; 21$ & $26 ; 20$ & $29 ; 19$ & $32 ; 18$ & $35 ; 17$ & $38 ; 16$ & $41 ; 15$ & $44 ; 14$ & $47 ; 13$ & $50 ; 12$ & $53 ; 11$ \\
\hline 12 & $4 ; 28$ & $7 ; 27$ & $10 ; 26$ & $13 ; 25$ & $16 ; 24$ & $19 ; 23$ & $22 ; 22$ & $25 ; 21$ & $28 ; 20$ & $31 ; 19$ & $34 ; 18$ & $37 ; 17$ & $40 ; 16$ & $43 ; 15$ & $46 ; 14$ & $49 ; 13$ & $52 ; 12$ \\
\hline 13 & $3 ; 29$ & $6 ; 28$ & $9 ; 27$ & $12 ; 26$ & $15 ; 25$ & $18 ; 24$ & $21 ; 23$ & $24 ; 22$ & $27 ; 21$ & $30 ; 20$ & $33 ; 19$ & $36 ; 18$ & $39 ; 17$ & $42 ; 16$ & $45 ; 15$ & $48 ; 14$ & $51 ; 13$ \\
\hline 14 & $2 ; 30$ & $5 ; 29$ & $8 ; 28$ & $11 ; 27$ & $14 ; 26$ & $17 ; 25$ & $20 ; 24$ & $23 ; 23$ & $26 ; 22$ & $29 ; 21$ & $32 ; 20$ & $35 ; 19$ & $38 ; 18$ & $41 ; 17$ & $44 ; 16$ & $47 ; 15$ & $50 ; 14$ \\
\hline 15 & $1 ; 31$ & $4 ; 30$ & $7 ; 29$ & $10 ; 28$ & $13 ; 27$ & $16 ; 26$ & $19 ; 25$ & $22 ; 24$ & $25 ; 23$ & $28 ; 22$ & $31 ; 21$ & $34 ; 20$ & $37 ; 19$ & $40 ; 18$ & $43 ; 17$ & $46 ; 16$ & $49 ; 15$ \\
\hline 16 & $0 ; 32$ & $3 ; 31$ & $6 ; 30$ & $9 ; 29$ & $12 ; 28$ & $15 ; 27$ & $18 ; 26$ & $21 ; 25$ & $24 ; 24$ & $27 ; 23$ & $30 ; 22$ & $33 ; 21$ & $36 ; 20$ & $39 ; 19$ & $42 ; 18$ & $48 ; 17$ & $48 ; 16$ \\
\hline
\end{tabular}

Table 1:... continued

2. Back transfer y out of $16+x$ (person $Y$ )

\begin{tabular}{|c|c|c|c|c|c|c|c|c|c|c|c|c|c|c|c|c|}
\hline & 17 & 18 & 19 & 20 & 21 & 22 & 23 & 24 & 25 & 26 & 27 & 28 & 29 & 30 & 31 & 32 \\
\hline 0 & - & - & - & - & - & - & - & - & - & - & - & - & - & - & - & - \\
\hline 1 & $66 ; 0$ & - & - & - & - & - & - & - & - & - & - & - & - & - & - & - \\
\hline 2 & $65 ; 1$ & $68 ; 0$ & - & - & - & - & - & - & - & - & - & - & - & - & - & - \\
\hline 3 & $64 ; 2$ & $67 ; 1$ & $70 ; 0$ & - & - & - & - & - & - & - & - & - & - & - & - & - \\
\hline 4 & $63 ; 3$ & $66 ; 2$ & $69 ; 1$ & $72 ; 0$ & - & - & - & - & - & - & - & - & - & - & - & - \\
\hline 5 & $62 ; 4$ & $65 ; 3$ & $68 ; 2$ & $71 ; 1$ & $74 ; 0$ & - & - & - & - & - & - & - & - & - & - & - \\
\hline 6 & $61 ; 5$ & $64 ; 4$ & $67 ; 3$ & $70 ; 2$ & $73 ; 1$ & $76 ; 0$ & - & - & - & - & - & - & - & - & - & - \\
\hline 7 & $60 ; 6$ & $63 ; 5$ & $66 ; 4$ & $69 ; 3$ & $72 ; 2$ & $75 ; 1$ & $78 ; 0$ & - & - & - & - & - & - & - & - & - \\
\hline 8 & $59 ; 7$ & $62 ; 6$ & $65 ; 5$ & $68 ; 4$ & $71 ; 3$ & $74 ; 2$ & $77 ; 1$ & $80 ; 0$ & - & - & - & - & - & - & - & - \\
\hline 9 & $58 ; 8$ & $61 ; 7$ & $64 ; 6$ & $67 ; 5$ & $70 ; 4$ & $73 ; 3$ & $76 ; 2$ & $79 ; 1$ & $82 ; 0$ & - & - & - & - & - & - & - \\
\hline 10 & $57 ; 9$ & $60 ; 8$ & $63 ; 7$ & $66 ; 6$ & $69 ; 5$ & $72 ; 4$ & $75 ; 3$ & $78 ; 2$ & $81 ; 1$ & $84 ; 0$ & - & - & - & - & - & - \\
\hline 11 & $56 ; 10$ & $59 ; 9$ & $62 ; 8$ & $65 ; 7$ & $68 ; 6$ & $71 ; 5$ & $74 ; 4$ & $77 ; 3$ & $80 ; 2$ & $83 ; 1$ & $86 ; 0$ & - & - & - & - & - \\
\hline 12 & $55 ; 11$ & $58 ; 10$ & $61 ; 9$ & $64 ; 8$ & $67 ; 7$ & $70 ; 6$ & $73 ; 5$ & $76 ; 4$ & $79 ; 3$ & $82 ; 2$ & $85 ; 1$ & $88 ; 0$ & - & - & - & - \\
\hline 13 & $54 ; 12$ & $57 ; 11$ & $60 ; 10$ & $63 ; 9$ & $66 ; 8$ & $69 ; 7$ & $72 ; 6$ & $75 ; 5$ & $78 ; 4$ & $81 ; 3$ & $84 ; 2$ & $87 ; 1$ & $90 ; 0$ & - & - & - \\
\hline 14 & $53 ; 13$ & $56 ; 12$ & $59 ; 11$ & $62 ; 10$ & $65 ; 9$ & $68 ; 8$ & $71 ; 7$ & $74 ; 6$ & $77 ; 5$ & $80 ; 4$ & $83 ; 3$ & $86 ; 2$ & $89 ; 1$ & $92 ; 0$ & - & - \\
\hline 15 & $52 ; 14$ & $55 ; 13$ & $58 ; 12$ & $61 ; 11$ & $64 ; 10$ & $67 ; 9$ & $70 ; 8$ & $73 ; 7$ & $76 ; 6$ & $79 ; 5$ & $82 ; 4$ & $85 ; 3$ & $88 ; 2$ & $91 ; 1$ & $94 ; 0$ & - \\
\hline 16 & $51 ; 15$ & $54 ; 14$ & $57 ; 13$ & $60 ; 12$ & $63 ; 11$ & $66 ; 10$ & $69 ; 9$ & $72 ; 8$ & $75 ; 7$ & $78 ; 6$ & $81 ; 5$ & $84 ; 4$ & $87 ; 3$ & $90 ; 2$ & $93 ; 1$ & $96 ; 0$ \\
\hline
\end{tabular}

Payoff person $X: 16-x+3 y$

Payoff person $Y$ (selected): $16+x-y$

Payoff person $Y$ (not selected): 16 
Table 2: Payoff table for the case that Person Y did donate (Payoff X; Payoff Y)

\begin{tabular}{|c|c|c|c|c|c|c|c|c|c|c|c|c|c|c|c|c|c|c|c|c|c|c|c|c|c|c|c|}
\hline \multicolumn{28}{|c|}{ 2. Back transfer y out of 10+x (person Y) } \\
\hline & 0 & 1 & 2 & 3 & 4 & 5 & 6 & 7 & 8 & 9 & 10 & 11 & 12 & 13 & 14 & 15 & 16 & 17 & 18 & 19 & 20 & 21 & 22 & 23 & 24 & 25 & 26 \\
\hline \multirow{6}{*}{ 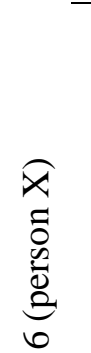 } & $16 ; 10$ & $19 ; 9$ & $22 ; 8$ & $25 ; 7$ & $28 ; 6$ & $31 ; 5$ & $34 ; 4$ & $37 ; 3$ & $40 ; 2$ & $43 ; 1$ & $46 ; 0$ & - & - & - & - & - & - & - & - & - & - & - & - & - & - & - & - \\
\hline & $15 ; 11$ & $18 ; 10$ & $21 ; 9$ & $24 ; 8$ & $27 ; 7$ & $30 ; 6$ & $33 ; 5$ & $36 ; 4$ & $39 ; 3$ & $42 ; 2$ & $45 ; 1$ & $48 ; 0$ & - & - & - & - & - & - & - & - & - & - & - & - & - & - & - \\
\hline & $14 ; 12$ & $17 ; 11$ & $20 ; 10$ & $23 ; 9$ & $26 ; 8$ & $29 ; 7$ & $32 ; 6$ & $35 ; 5$ & $38 ; 4$ & $41 ; 3$ & $44 ; 2$ & $47 ; 1$ & $50 ; 0$ & - & - & - & - & - & - & - & - & - & - & - & - & - & - \\
\hline & $13 ; 13$ & $16 ; 12$ & $19 ; 11$ & $22 ; 10$ & $25 ; 9$ & $28 ; 8$ & $31 ; 7$ & $34 ; 6$ & $37 ; 5$ & $40 ; 4$ & $43 ; 3$ & $46 ; 2$ & $49 ; 1$ & $52 ; 0$ & - & - & - & - & - & - & - & - & - & - & - & - & - \\
\hline & $12 ; 14$ & $15 ; 13$ & $18 ; 12$ & $21 ; 11$ & $24 ; 10$ & $27 ; 9$ & $30 ; 8$ & $33 ; 7$ & $36 ; 6$ & $39 ; 5$ & $42 ; 4$ & $45 ; 3$ & $48 ; 2$ & $51 ; 1$ & $54 ; 0$ & - & - & - & - & - & - & - & - & - & - & - & - \\
\hline & $11 ; 15$ & $14 ; 14$ & $17 ; 13$ & $20 ; 12$ & $23 ; 11$ & $26 ; 10$ & $29 ; 9$ & $32 ; 8$ & $35 ; 7$ & $38 ; 6$ & $41 ; 5$ & $44 ; 4$ & $47 ; 3$ & $50 ; 2$ & $53 ; 1$ & $56 ; 0$ & - & - & - & - & - & - & - & - & - & - & - \\
\hline 6 & $10 ; 16$ & $13 ; 15$ & $16 ; 14$ & $19 ; 13$ & $22 ; 12$ & $25 ; 11$ & $28 ; 10$ & $31 ; 9$ & $34 ; 8$ & $37 ; 7$ & $40 ; 6$ & $43 ; 5$ & $46 ; 4$ & $49 ; 3$ & $52 ; 2$ & $55 ; 1$ & $58 ; 0$ & - & - & - & - & - & - & - & - & - & - \\
\hline \multirow{6}{*}{ 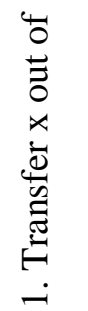 } & $9 ; 17$ & $12 ; 16$ & $15 ; 15$ & $18 ; 14$ & $21 ; 13$ & $24 ; 12$ & $27 ; 11$ & $30 ; 10$ & $33 ; 9$ & $36 ; 8$ & $39 ; 7$ & $42 ; 6$ & $45 ; 5$ & $48 ; 4$ & $51 ; 3$ & $54 ; 2$ & $57 ; 1$ & $60 ; 0$ & - & - & - & - & - & - & - & - & - \\
\hline & $8 ; 18$ & $11 ; 17$ & $14 ; 16$ & $17 ; 15$ & $20 ; 14$ & $23 ; 13$ & $26 ; 12$ & $29 ; 11$ & $32 ; 10$ & $35 ; 9$ & $38 ; 8$ & $41 ; 7$ & $44 ; 6$ & $47 ; 5$ & $50 ; 4$ & $53 ; 3$ & $56 ; 2$ & $59 ; 1$ & $62 ; 0$ & - & - & - & - & - & - & - & - \\
\hline & $7 ; 19$ & $10 ; 18$ & $13 ; 17$ & $16 ; 16$ & $19 ; 15$ & $22 ; 14$ & $25 ; 13$ & $28 ; 12$ & $31 ; 11$ & $34 ; 10$ & $37 ; 9$ & $40 ; 8$ & $43 ; 7$ & $46 ; 6$ & $49 ; 5$ & $52 ; 4$ & $55 ; 3$ & $58 ; 2$ & $61 ; 1$ & $64 ; 0$ & - & - & - & - & - & - & - \\
\hline & $6 ; 20$ & $9 ; 19$ & $12 ; 18$ & $15 ; 17$ & $18 ; 16$ & $21 ; 15$ & $24 ; 14$ & $27 ; 13$ & $30 ; 12$ & $33 ; 11$ & $36 ; 10$ & $39 ; 9$ & $42 ; 8$ & $45 ; 7$ & $48 ; 6$ & $51 ; 5$ & $54 ; 4$ & $57 ; 3$ & $60 ; 2$ & $63 ; 1$ & $66 ; 0$ & - & - & - & - & - & - \\
\hline & $5 ; 21$ & $8 ; 20$ & $11 ; 19$ & $14 ; 18$ & $17 ; 17$ & $20 ; 16$ & $23 ; 15$ & $26 ; 14$ & $29 ; 13$ & $32 ; 12$ & $35 ; 11$ & $38 ; 10$ & $41 ; 9$ & $44 ; 8$ & $47 ; 7$ & $50 ; 6$ & $53 ; 5$ & $56 ; 4$ & $59 ; 3$ & $62 ; 2$ & $65 ; 1$ & $68 ; 0$ & - & - & - & - & - \\
\hline & $4 ; 22$ & $7 ; 21$ & $10 ; 20$ & $13 ; 19$ & $16 ; 18$ & $19 ; 17$ & $22 ; 16$ & $25 ; 15$ & $28 ; 14$ & $31 ; 13$ & $34 ; 12$ & $37 ; 11$ & $40 ; 10$ & $43 ; 9$ & $46 ; 8$ & $49 ; 7$ & $52 ; 6$ & $55 ; 5$ & $58 ; 4$ & $61 ; 3$ & $64 ; 2$ & $67 ; 1$ & $70 ; 0$ & - & - & - & - \\
\hline 13 & $3 ; 23$ & $6 ; 22$ & $9 ; 21$ & $12 ; 20$ & $15 ; 19$ & $18 ; 18$ & $21 ; 17$ & $24 ; 16$ & $27 ; 15$ & $30 ; 14$ & $33 ; 13$ & $36 ; 12$ & $39 ; 11$ & $42 ; 10$ & $45 ; 9$ & $48 ; 8$ & $51 ; 7$ & $54 ; 6$ & $57 ; 5$ & $60 ; 4$ & $63 ; 3$ & $66 ; 2$ & $69 ; 1$ & $72 ; 0$ & - & - & - \\
\hline 14 & $2 ; 24$ & $5 ; 23$ & $8 ; 22$ & $11 ; 21$ & $14 ; 20$ & $17 ; 19$ & $20 ; 18$ & $23 ; 17$ & $26 ; 16$ & $29 ; 15$ & $32 ; 14$ & $35 ; 13$ & $38 ; 12$ & $41 ; 11$ & $44 ; 10$ & $47 ; 9$ & $50 ; 8$ & $53 ; 7$ & $56 ; 6$ & $59 ; 5$ & $62 ; 4$ & $65 ; 3$ & $68 ; 2$ & $71 ; 1$ & $74 ; 0$ & - & - \\
\hline 15 & $1 ; 25$ & $4 ; 24$ & $7 ; 23$ & $10 ; 22$ & $13 ; 21$ & $16 ; 20$ & $19 ; 19$ & $22 ; 18$ & $25 ; 17$ & $28 ; 16$ & $31 ; 15$ & $34 ; 14$ & $37 ; 13$ & $40 ; 12$ & $43 ; 11$ & $46 ; 10$ & $49 ; 9$ & $52 ; 8$ & $55 ; 7$ & $58 ; 6$ & $61 ; 5$ & $64 ; 4$ & $67 ; 3$ & $70 ; 2$ & $73 ; 1$ & $76 ; 0$ & - \\
\hline 16 & $0 ; 26$ & $3 ; 25$ & $6 ; 24$ & $9 ; 23$ & $12 ; 22$ & $15 ; 21$ & $18 ; 20$ & $21 ; 19$ & $24 ; 18$ & $27 ; 17$ & $30 ; 16$ & $33 ; 15$ & $36 ; 14$ & $39 ; 13$ & $42 ; 12$ & $45 ; 11$ & $48 ; 10$ & $51 ; 9$ & $54 ; 8$ & $57 ; 7$ & $60 ; 6$ & $63 ; 5$ & $66 ; 4$ & $69 ; 3$ & $72 ; 2$ & $75 ; 1$ & $78 ; 0$ \\
\hline
\end{tabular}

Payoff person X: 16-x+3y

Payoff person $Y$ (selected): $10+x-y$

Payoff person Y (not selected): 10 